\title{
2-Hydroxychalcone as a Potent Compound and Photosensitizer Against Dermatophyte Biofilms
}

\author{
Níura Madalena Bila ${ }^{1,2}$, Caroline Barcelos Costa-Orlandi ${ }^{1}$, Carolina Orlando Vaso ${ }^{1}$, \\ Jean Lucas Carvalho Bonatti ${ }^{1}$, Letícia Ribeiro de Assis ${ }^{3}$, Luís Octavio Regasini ${ }^{3}$, \\ Carla Raquel Fontana ${ }^{1}$, Ana Marisa Fusco-Almeida ${ }^{1}$ and Maria José Soares Mendes-Giannini ${ }^{1{ }^{*}}$ \\ 1 Department of Clinical Analysis, School of Pharmaceutical Sciences, Universidade Estadual Paulista (UNESP), Araraquara, \\ Brazil, 2 Department of Para-Clinic, School of Veterinary, Universidade Eduardo Mondlane (UEM), Maputo, Mozambique, \\ ${ }^{3}$ Department of Chemistry and Environmental Sciences, Institute of Biosciences, Humanities and Exact Sciences, \\ Universidade Estadual Paulista (UNESP), Sao Jose do Rio Preto, Brazil
}

OPEN ACCESS

Edited by: Yong-Sun Bahn, Yonsei University, South Korea

Reviewed by: Ping Wang, Louisiana State University, United States Hee-Soo Park, Kyungpook National University, South Korea

${ }^{*}$ Correspondence: Maria José Soares Mendes-Giannini gianninimj@gmail.com; maria.giannini@unesp.br

Specialty section: This article was submitted to Fungal Pathogenesis, a section of the journal Frontiers in Cellular and Infection Microbiology

Received: 11 March 2021 Accepted: 23 April 2021 Published: 13 May 2021

Citation:

Bila NM, Costa-Orlandi CB, Vaso CO, Bonatti JLC, de Assis LR, Regasini LO, Fontana CR, Fusco-Almeida AM and Mendes-Giannini MJS (2021)

2-Hydroxychalcone as a Potent Compound and Photosensitizer Against Dermatophyte Biofilms. Front. Cell. Infect. Microbiol. 11:679470. doi: 10.3389/fcimb.2021.679470
Dermatophytes, fungi that cause dermatophytosis, can invade keratinized tissues in humans and animals. The biofilm-forming ability of these fungi was described recently, and it may be correlated with the long treatment period and common recurrences of this mycosis. In this study, we evaluated the anti-dermatophytic and anti-biofilm activity of 2hydroxychalcone (2-chalcone) in the dark and photodynamic therapy (PDT)-mediated and to determine its mechanism of action. Trichophyton rubrum and Trichophyton mentagrophytes strains were used in the study. The antifungal susceptibility test of planktonic cells, early-stage biofilms, and mature biofilms were performed using colorimetric methods. Topographies were visualized by scanning electron microscopy (SEM). Human skin keratinocyte (HaCat) monolayers were also used in the cytotoxicity assays. The mechanisms of action of 2-chalcone in the dark and under photoexcitation were investigated using confocal microscopy and the quantification of ergosterol, reactive oxygen species (ROS), and death induction by apoptosis/necrosis. All strains, in the planktonic form, were inhibited after treatment with 2-chalcone (minimum inhibitory concentration $(\mathrm{MIC})=7.8-15.6 \mathrm{mg} / \mathrm{L})$, terbinafine $(\mathrm{TRB})(\mathrm{MIC}=0.008-0.03 \mathrm{mg} / \mathrm{L})$, and fluconazole (FLZ) (1-512 mg/L). Early-stage biofilm and mature biofilms were inhibited by 2-chalcone at concentrations of $15.6 \mathrm{mg} / \mathrm{L}$ and $31.2 \mathrm{mg} / \mathrm{L}$ in all tested strains. However, mature biofilms were resistant to all the antifungal drugs tested. When planktonic cells and biofilms (early-stage and mature) were treated with 2-chalcone-mediated PDT, the inhibitory concentrations were reduced by four times (2-7.8 mg/L). SEM images of biofilms treated with 2-chalcone showed cell wall collapse, resulting from a probable extravasation of cytoplasmic content. The toxicity of 2-chalcone in HaCat cells showed higher $I_{50}$ values in the dark than under photoexcitation. Further, 2-chalcone targets ergosterol in the cell and promotes the generation of ROS, resulting in cell death by apoptosis and necrosis. Overall, 2-chalcone-mediated PDT is a promising and safe drug candidate against dermatophytes, particularly in anti-biofilm treatment.

Keywords: dermatophytes, biofilms, 2-chalcone, photodynamic therapy, mechanism of action, Trichophyton rubrum, T. mentagrophytes 


\section{INTRODUCTION}

Dermatophytes are filamentous fungi that may infect keratinized structures such as the skin, hair, and nails of humans and animals, causing dermatophytosis (Costa-Orlandi et al., 2014; Heidrich et al., 2015; Maraki and Mavromanolaki, 2016). This disease is globally considered as the most common dermatological zoonosis, with a prevalence of $20-25 \%$ in the global human population (Ivaskiene et al., 2016).

Phylogenetic re-taxonomy has been proposed for dermatophytes, suggesting their division into six genera (Zhan and Liu, 2017) and into nine genera (De Hoog et al., 2017). Nevertheless, the principal genera include Trichophyton, Microsporum, and Epidermophyton (Moriello, 2004; CostaOrlandi et al., 2014; Maraki and Mavromanolaki, 2016; De Hoog et al., 2017). Dermatophytes can be grouped as anthropophilic, zoophilic, and geophilic (Moriello, 2004; Ivaskiene et al., 2016). T. rubrum is the most prevalent dermatophyte species, accounting for more than $80 \%$ of all infections. This species is commonly isolated in cases of tinea unguium, tinea corporis, tinea cruris, and tinea pedis (Faway et al., 2016; Zhan and Liu, 2017).

One of the main virulence factors of fungal species is the formation of communities called biofilms (Costa-Orlandi et al., 2017). In vitro biofilm formation by two of the most prevalent dermatophyte species, T. rubrum and T. mentagrophytes, was described (Costa-Orlandi et al., 2014) and was soon demonstrated in Microsporum canis (Danielli et al., 2017). In vivo biofilm formation by dermatophytes in patients with dermatophytosis is currently under investigation. However, a hypothetical relationship has been reported between biofilm formation and the persistent clinical condition of onychomycosis infections that have firm white masses of adhesion and are challenging to remove and treat (Burkhart; Burkhart; Gupta, 2002; Gupta, Daigle, Carviel, 2016; Gupta and Foley, 2019).

Although a reasonable number of antifungal drugs are available for treating dermatophytosis, there has been little progress in new drug development in the last two decades, and recurrences in onychomycosis cases have increased by $50 \%$ (Gupta, Daigle, Carviel, 2016; Singh et al., 2018a). Most of these drugs are classified into two families: azoles and allylamines (Gupta and Cooper, 2008; Aggarwal and Goindi, 2012). Azole derivatives, other than terbinafine and naftifine, are commonly prescribed to topically treat superficial infections in the early stages (Makimura et al., 1999; Gupta and Cooper, 2008; Aggarwal and Goindi, 2012). In extensive infections, chronic infections, or onychomycosis, oral drugs such as terbinafine, itraconazole, fluconazole, griseofulvin, and ketoconazole are used (Gupta and Cooper, 2008; Aggarwal and Goindi, 2012; Aggarwal et al., 2020). Due to the long treatment period for these infections, coupled with the considerable toxicity of most oral antifungal agents, monitoring is necessary for the hepatic, renal, and hematopoietic functions (Gupta and Cooper, 2008; Gupta,Versteeg, Shear, 2017a).

Difficult eradication, drug toxicity, and high recurrence rate have encouraged the search for therapeutic alternatives for dermatophytosis, mainly if they are associated with biofilm formation. The anti-dermatophyte effects of essential oils from plants (Mahboubi; Heidarytabar; Mahdizadeh, 2017), plant extracts (Mahboubi; Kazempour, 2015; Sun et al., 2017), ozone gas, ozonized oil (Ouf et al., 2016), and photodynamic inactivation (Paz-Cristobal et al., 2014; De Oliveira et al., 2015; Shamali et al., 2018), have already been described.

Chalcones or 1,3-diphenyl-2-propen-1-one are polyhydroxy compound precursors for flavonoids and isoflavonoids, which are abundant in fruits, vegetables, and edible plants (Gupta; Jain, 2015; Fu et al., 2016; Karimi-Sales; Mohaddes; Alipour, 2017). However, these compounds can be synthesized in the laboratory using the Claisen-Schmidt condensation method (Karimi-Sales; Mohaddes; Alipour, 2017). Chalcones demonstrate many biological activities such as anti-inflammatory, anti-tumor (Khanapure et al., 2018), antioxidant (Singh et al., 2018b), antidiabetic (Cai et al., 2017), antibacterial (Singh et al., 2018a), antifungal (Gupta; Jain, 2015; Fu et al., 2016; Illicachi et al., 2017), antiprotozoal (Illicachi et al., 2017; Tajuddeen et al., 2018), and antiparasitic (Kotlyar et al., 2019), as well as activities against Alzheimer's disease (Zhang et al., 2018b) and cholinesterase inhibition (Shah et al., 2018) among others. Chalcones can be excellent photosensitizers for PDT. For instance, photodynamic inactivation has been demonstrated in Histoplasma capsulatum (Melo et al., 2017).

PDT is a non-invasive treatment comprising the use of laser light or light-emitting diode (LED) of a specific wavelength that activates a photosensitive agent in the presence of oxygen, which results in the production of reactive oxygen species (ROS), free radicals, and consequently, cell death (Davies et al., 2016; De Figueiredo Freitas et al., 2017; Yang et al., 2018; Yuan et al., 2017). PDT is a promising modality as it is effective against a wide range of microorganism species (De Figueiredo Freitas et al., 2017). Photodynamic inactivation of microorganisms can occur in strains that are susceptible or resistant to conventional drugs (Mai et al., 2017). Therefore, this study aimed to evaluate the efficacy of 2chalcone in the dark and of 2-chalcone-mediated PDT against dermatophyte biofilms, as well as to investigate its toxicity and mechanism of action in human skin keratinocytes (HaCat).

\section{MATERIALS AND METHODS}

\section{Microorganisms and Synthesis of 2-Chalcone}

T. rubrum ATCC 28189, ATCC MYA-4438, and $T$. mentagrophytes ATCC 11481 were used in this study. All strains were obtained from the Clinical Mycology Laboratory of the Department of Clinical Analysis, Faculty of Pharmaceutical Sciences-UNESP, Brazil. Microorganisms were grown on malt extract agar [malt extract (Kasvi): $2 \%$, peptone from animal tissue (Sigma-Aldrich): $2 \%$, glucose (Synth): $2 \%$ and agar (Kasvi): $2 \%$ ], $\mathrm{pH} 5.7$, incubated at $28^{\circ} \mathrm{C}$ for 7 days or until sporulation (Garcia et al., 2020).

Synthesis of 2-chalcone was performed as described by Melo et al. (2017) in collaboration with Prof. Dr. Luis Octávio Regasini's research group from the Institute of Biosciences, Letters and Exact Sciences-UNESP, Brazil. The compound was 
functionalized by adding one hydroxyl group on carbon-2 to increase its solubility in aqueous medium.

\section{In Vitro Susceptibility of Dermatophytes to 2-Chalcone and Antifungal Drugs and Determination of Minimum Fungicide Concentration (MFC)}

\section{Determination of the Minimum Inhibitory}

\section{Concentration (MIC)}

Susceptibility tests were performed according to the document M38-A2, proposed by the Clinical Laboratory Standards Institute (CLSI) (2008), with a minor modification of addition of resazurin (Costa-Orlandi et al., 2020). Briefly, 2-chalcone was solubilized in $100 \%$ dimethyl sulfoxide (DMSO) at a stock concentration of $30,000 \mathrm{mg} / \mathrm{L}$ and was stored at $-80^{\circ} \mathrm{C}$. The working solutions of $2-$ chalcone at concentrations ranging from 0.12 to $62.5 \mathrm{mg} / \mathrm{L}$ were prepared in Roswell Park Memorial Institute (RPMI)-1640 medium with L-glutamine, without sodium bicarbonate, and with phenol red as the $\mathrm{pH}$ indicator $\left(G i b c o^{\circledR}\right)$, and buffered with 4-Morpholinepropanesulfonic acid hemisodium salt (MOPS) (Sigma-Aldrich), $\mathrm{pH}=7$. TRB (Sigma-Aldrich) (0.5$0.001 \mathrm{mg} / \mathrm{L})$, FLZ (Sigma-Aldrich) $(0.12-64 \mathrm{mg} / \mathrm{L})$, and the $T$. rubrum ATCC MYA-4438 were also used for quality control. Fungal suspensions were prepared in $0.85 \% \mathrm{NaCl}$ and conidia were adjusted to a final concentration of $2.5 \times 10^{3}$ cells $/ \mathrm{mL}$ using a hemocytometer, before adding to microdilution plates. Dilutions of the compound and antifungal drugs were dispensed in a 96well microplate (Kasvi) at a total volume of $100 \mu \mathrm{L} /$ well, following $100 \mu \mathrm{L}$ of the inoculum. Visual and colorimetric readings were performed by adding $30 \mu \mathrm{L}$ of $0.03 \%$ resazurin. Resazurin is a blue reagent that is reduced to pink-colored resorufin in the presence of viable cells (Scorzoni et al., 2007; Costa-Orlandi et al., 2014; Aneke; Otranto; Cafarchia, 2018).

\section{Determination of the MFC}

The MFC was determined as described by Costa-Orlandi et al. (2020). Aliquots from each well of the MIC assay microdilution plate were added to Petri dishes containing Sabouraud Dextrose agar (BD Difco ${ }^{\mathrm{TM}}$ ) and incubated at $28^{\circ} \mathrm{C}$ for 96 hours. The MFC is defined as the lowest concentration of the compound that shows no growth of fungal colonies.

\section{Susceptibility Assay of Early-Stage Biofilms and Mature Biofilms Against 2-Chalcone and Antifungal Drugs}

The biofilm susceptibility assay was based on the protocol described by Pierce et al. (2008) modified by Costa-Orlandi et al. (2020). Early-stage (24 hours) and mature (96 hours) biofilms, formed in the 96 -well plates as described by CostaOrlandi (2014), were washed with sterile phosphate-buffered saline (PBS). Two hundred microliters of 2-chalcone solution and antifungals diluted in RPMI-1640 medium were added to the plates containing biofilms and incubated at $37^{\circ} \mathrm{C}$ for 96 hours. Metabolic activity was then measured using the XTT (2,3-Bis-(2Methoxy-4-Nitro-5-Sulfophenyl)-2H-Tetrazolium-5Carboxanilide) reduction assay. Inhibition was considered as the reduction of at least $50 \%$ metabolic activity compared to the control without treatment.

\section{Effect of Antifungal Drugs and 2-Chalcone on Planktonic Cells $\left(10^{6}\right.$ cells $\left./ \mathrm{mL}\right)$}

The protocol used to evaluate antifungal drugs and 2-chalcone in biofilms was also applied to the planktonic cells and at the same concentration used for biofilm formation $\left(1 \times 10^{6}\right.$ cells $\left./ \mathrm{mL}\right)$ to compare the susceptibility of cells in the two different forms. Fungal suspensions were prepared to obtain a final concentration of $1 \times 10^{6}$ cells $/ \mathrm{mL}$. One hundred microliters of suspensions placed in the 96-well plates (Kasvi), $100 \mu \mathrm{L}$ of the working solutions of the compound $(1-500 \mathrm{mg} / \mathrm{L})$ and the antifungal agents TRB (0.002-1 mg/L) and FLZ (1-512 mg/L) were diluted in RPMI-1640 medium with the same specifications previously described. The plates were then incubated at $37^{\circ} \mathrm{C}$ for 96 hours, and the XTT reduction assay was used to quantify the metabolic activity of cells as described by Martinez and Casadevall (2006) and Pierce et al. (2008) with minor modifications. Briefly, $50 \mu \mathrm{L}$ of the XTT solution and $4 \mu \mathrm{L}$ of menadione were added to the suspensions in the wells and incubated for 3 hours. The absorbance was measured using a microplate reader (Epoch, Biotek) at $490 \mathrm{~nm}$

\section{Photodynamic Therapy Assay}

A blue LED (IrradLED ${ }^{\circledR}$-Biopdi, Sao Carlos, SP, Brazil) with a wavelength range between $455 \mathrm{~nm}$ and $492 \mathrm{~nm}$, was used as the light source. Intensity was maintained at $58 \mathrm{~mW} / \mathrm{cm}^{2}$, and the administered dose was $150 \mathrm{~J} / \mathrm{cm}^{2}$. The photosensitization assay was performed as described by Baltazar et al. (2013), with minor modifications. Briefly, biofilms were prepared as previously described, without phenol red in RPMI-1640 (Sigma-Aldrich) medium. Then, early-stage and mature biofilms were washed with sterile PBS and placed in contact with different concentrations of 2-chalcone $(0.25-125 \mathrm{mg} / \mathrm{L})$. The plates were incubated for 10 minutes in the dark and at $25^{\circ} \mathrm{C}$ and were then irradiated. After irradiation, the plates were incubated at $37^{\circ} \mathrm{C}$ for 96 hours. The analysis of the metabolic activity of cells was done by the XTT reduction assay.

\section{Topographic Analysis of Biofilms by Scanning Electron Microscopy (SEM)}

Early-stage and mature biofilms treated with 2-chalcone were processed as described by Martinez et al. (2010) and CostaOrlandi et al. (2014). Biofilms were formed in 24-well plates, washed three times with PBS, and fixed with $800 \mu \mathrm{L}$ of $2.5 \%$ glutaraldehyde solution (Sigma-Aldrich) for 1 hour at $4^{\circ} \mathrm{C}$. The samples were then dehydrated with increasing ethyl alcohol concentrations $(50-100 \%)$ at $25^{\circ} \mathrm{C}$ and were subsequently dried under the same conditions. Before microscopic analysis, the plate's bottom containing the samples was cut with a scalpel, mounted on aluminum cylinders with silver (stubs), and placed on a high vacuum evaporator (Denton Vacuum Desk V, Jeol USA) for gold plating. The damage to the biofilm topography was analyzed using a scanning electron microscope Jeol JSM6610LV at the School of Dentistry, UNESP-Araraquara, Brazil. 


\section{Cytotoxicity Assay for 2-Chalcone in Human Skin Keratinocytes (HaCat)}

The cytotoxicity assay aimed to verify the selectivity index (SI) after the treatment of planktonic cells and mature biofilms with 2chalcone in the dark and 2-chalcone-mediated PDT. The assay was performed as described by Costa-Orlandi et al. (2020) with minor modifications. Briefly, HaCat cells (CLS Cell Lines Service, 300493) were maintained in cell culture bottles with Dulbecco's modified eagle's medium (DMEM), containing 10\% fetal bovine serum without phenol red, and incubated under standard conditions $\left(37^{\circ} \mathrm{C}, 5 \% \mathrm{CO}_{2}\right)$. Cell suspensions were prepared to obtain a final concentration of $2 \times 10^{4}$ cells/well in a 96-well microdilution plate. After 24 hours of incubation, the culture medium was removed and $200 \mu \mathrm{L}$ of different concentrations of 2-chalcone were added. On some plates, photosensitization of 2-chalcone at $150 \mathrm{~J} . \mathrm{cm}^{-2}$ was performed, and the others were kept in the dark. All the plates were incubated for 72 hours in the same conditions and protected from light. After incubation, $20 \mu \mathrm{L}$ of resazurin (Sigma-Aldrich) at 60 $\mu \mathrm{M}$ was added and the plates were further incubated for 8 hours. Cell viability was assessed based on spectrophotometric (Epoch, Biotek) analysis at wavelengths $570 \mathrm{~nm}$ and $600 \mathrm{~nm}$.

\section{Determination of the Mechanism of Action Laser Scanning Confocal Microscopy}

Confocal microscopy was used to evaluate the damage to the cell wall caused by 2-chalcone, using fluorochrome Calcofluor White (Thermo Fisher Scientific) and T. rubrum ATCC 28189. Fungal suspensions were prepared at a concentration of $1 \times 10^{6}$ cells $/ \mathrm{mL}$ and added to 24 -well plates containing sterile coverslips, along with sub-inhibitory doses of 2 -chalcone $(7.8 \mathrm{mg} / \mathrm{L})$. After the incubation period $\left(35^{\circ} \mathrm{C}\right.$, for 96 hours), the supernatant was removed and the coverslips were washed with PBS. The coverslips were covered with Calcofluor White solution (100 $\mathrm{mg} / \mathrm{L}$ ), and the plates were incubated again at $37^{\circ} \mathrm{C}$, for 45 minutes, protected from light. Then, the coverslips were washed with PBS, removed from the wells, and mounted on $4 \mu \mathrm{L}$ of Fluoromount-G (Sigma-Aldrich), which was previously deposited on microscopic slides. The slides were then observed using a confocal microscope (Carl Zeiss LSM 800 with Airyscan) with an image capture and processing program (Software ZEN BLUE 2.3 System) at the Faculty of Dentistry, UNESPAraraquara, Brazil (Curcio et al., 2017; Oliveira et al., 2020).

\section{Quantification of Membrane Ergosterol}

Ergosterol quantification was performed as described by Arthington-Skaggs et al. (1999) with minor modifications. Briefly, sub-inhibitory concentrations of 2-chalcone in the dark (7.8 mg/L), 2-chalcone-mediated PDT (1 mg/L), FLZ (128 mg/ $\mathrm{L})$, and amphotericin $\mathrm{B}(\mathrm{AMB})(1 \mathrm{mg} / \mathrm{L})$ were used to treat a suspension of T. rubrum ATCC 28189 at a final concentration of $1 \times 10^{6}$ cells $/ \mathrm{mL}$ (diluted in RPMI-1640). The samples were incubated at $35^{\circ} \mathrm{C}$, under agitation at $150 \mathrm{rpm}$ for five days. After incubation, the samples were centrifuged and washed with sterile distilled water, and $3 \mathrm{ml}$ of $25 \%$ alcoholic $\mathrm{KOH}$ solution was added. For sterol extraction, the samples were incubated in a water bath at $85^{\circ} \mathrm{C}$ for 1 hour after being transferred to glass tubes with a screw cap. The samples were cooled at $25^{\circ} \mathrm{C}$, mixed with $1 \mathrm{~mL}$ of sterile distilled water, $3 \mathrm{~mL}$ of $\mathrm{n}$-heptane, and sterile glass beads, followed by homogenization for 10 minutes on a vortex. The resulting supernatant (n-heptane layer) was transferred to microtubes and incubated at $-20^{\circ} \mathrm{C}$ for 24 hours followed by an analysis on a visible UV spectrophotometer at a wavelength of $281 \mathrm{~nm}$. Standard curves were prepared using 95\% pure ergosterol at concentrations ranging from 75 to $10 \mathrm{mg} / \mathrm{L}$.

\section{Apoptosis/Necrosis Assay}

The death mechanism in T. rubrum ATCC 28189 was studied after treatment with 2-chalcone in the dark, 2-chalconemediated PDT, AMB, and FLZ. Inocula were prepared and adjusted to a final concentration of $1 \times 10^{6}$ cells $/ \mathrm{mL}$ in a volume of $1.5 \mathrm{~mL}$. The cells were treated with the same volume of compounds and AMB at a concentration of $4 \mathrm{x}$ MIC. FLZ treatment was performed at a concentration of $256 \mathrm{mg} / \mathrm{L}$ (as this strain was found to be resistant to FLZ). Cell death was evaluated using the Annexin V-FITC apoptosis detection kit (Sigma-Aldrich, A9210) following the manufacturer's guidelines. The samples were analyzed on a BD FACS Canto I flow cytometer located at the Clinical Mycology Laboratory at the School of Pharmaceutical Sciences, UNESP-Araraquara, Brazil.

\section{Quantification of ROS}

Intracellular ROS production after treating T. rubrum ATCC 28189 with 2-chalcone in the dark and 2-chalcone mediated PDT was evaluated using $50 \mu \mathrm{M}$ H2DCFDA (2.7 dichlorodihydrofluorescein diacetate, Invitrogen) as described by Singulani et al. (2019). This compound is converted to a highly fluorescent $2^{\prime}, 7^{\prime}$ dichlorofluorescein (DCF) compound after cleavage of its acetate group by intracellular esterases and this compound binds to ROS. As controls, AMB and FLZ treatments were used. The treatment was performed as described apoptosis/necrosis assay section. After the incubation period, the samples were washed, following suspension in $500 \mu \mathrm{L}$ of PBS, and transferred to cytometer tubes. Then, $1.5 \mu \mathrm{L}$ of the H2DCFDA solution was added with subsequent incubation at $25^{\circ} \mathrm{C}$ in the dark for 10 minutes. The samples were analyzed on a BD FACS Canto I flow cytometer.

\section{Data Analysis}

All data from this study are representative of at least three independent and triplicate experiments. GraphPad Prism 5.0 software (GraphPad Software Inc., La Jolla, CA) was used to construct graphs and for statistical analysis. Non-linear semi-log regression was performed to obtain the $\mathrm{IC}_{50}$ for treated HaCat cells. Analysis of variance with Bonferroni post-hoc test was applied to the other graphs. Differences with $\mathrm{p}<0.05$ were considered statistically significant.

\section{RESULTS}

\section{Determination of MIC and MFC}

The results of the antifungal activities of 2-chalcone, TRB, and FLZ against dermatophyte species are shown in Table 1. In all 
strains tested, 2-chalcone had a MIC of $7.8 \mathrm{mg} / \mathrm{L}$. TRB had a MIC of $0.03 \mathrm{mg} / \mathrm{L}$ in $T$. rubrum strains and $0.008 \mathrm{mg} / \mathrm{L}$ in $T$. mentagrophytes strain. On the contrary, T. rubrum ATCC 28189 was resistant to FLZ with a MIC of $64 \mathrm{mg} / \mathrm{L}$, whereas the remaining strains, T. rubrum ATCC MYA-4438 and T. mentagrophytes ATCC 11481, were susceptible to FLZ (with MIC $4 \mathrm{mg} / \mathrm{L}$ and $1 \mathrm{mg} / \mathrm{L}$, respectively).

The MFC for 2-chalcone corresponded to $15.6 \mathrm{mg} / \mathrm{L}$, double the MIC, in all strains tested. The same trend was observed in the TRB results. FLZ had a MFC of 16,32 , and $>64 \mathrm{mg} / \mathrm{L}$ in $T$. mentagrophytes ATCC 11481, T. rubrum ATCC MYA-4438, and T. rubrum ATCC 28189, respectively.

\section{Effect of 2-Chalcone and Antifungal Drugs on Early-Stage and Mature Biofilms}

From $15.6 \mathrm{mg} / \mathrm{L}, 2$-chalcone inhibited the metabolic activity of early-stage biofilms of the three strains tested, with approximately $90 \%$ reduction in cell viability when compared to the control without treatment $(\mathrm{p}<0.001)$ (Figure 1A). TRB inhibited earlystage biofilms of T. mentagrophytes ATCC 11481, T. rubrum ATCC MYA-4438, and T. rubrum ATCC 28289 from concentrations of $0.06,1$, and $32 \mathrm{mg} / \mathrm{L}$, respectively $(\mathrm{p}<0.001)$ (Figure 1B). However, FLZ only inhibited the biofilms formed by the T. mentagrophytes ATCC 11481 from $32 \mathrm{mg} / \mathrm{L}$ ( $\mathrm{p}<0.001)$ (Figure 1C).

In mature biofilms, 2-chalcone showed potent anti-biofilm activity, and inhibited the metabolic activity by about $90 \%$ in all fungi tested from the concentration of $31.25 \mathrm{mg} / \mathrm{L}(\mathrm{p}<0.001)$ (Figure 2A). In contrast, TRB and FLZ did not show anti-biofilm activity at all the different concentrations tested (Figures 2B, C).

\section{Effect of 2-Chalcone and Antifungal Drugs on Planktonic Cells at a Concentration of $10^{6} \mathrm{cells} / \mathrm{mL}$}

The effect of 2-chalcone and of the drugs TRB and FLZ on planktonic cells was verified at the same concentration used for biofilm formation $\left(1 \times 10^{6}\right.$ cells $\left./ \mathrm{mL}\right)$ by measuring the metabolic activity of the cells. The results showed that 2-chalcone could reduce the metabolic activity of T. rubrum ATCC 28189 from the concentration of $7.8 \mathrm{mg} / \mathrm{L}$ ( $\mathrm{p}<0.001$ ) of T. rubrum ATCC MYA4438 and T. mentagrophytes ATCC 1148 from $15.6 \mathrm{mg} / \mathrm{L}$ ( $\mathrm{p}<$ 0.001) (Figure 3A). TRB was potent in T. mentagrophytes ATCC 1148 with a reduction in metabolic activity from the concentration of $0.008 \mathrm{mg} / \mathrm{L}$, and in T. rubrum ATCC MYA4438 and T. rubrum ATCC 28189 from $0.03 \mathrm{mg} / \mathrm{L}$ and $0.06 \mathrm{mg} /$ $\mathrm{L}$, respectively $(\mathrm{p}<0.001)$ (Figure $3 \mathrm{~B})$. Besides, FLZ was less potent than TRB, with reduced metabolic activity from the concentration of 64,256 , and $512 \mathrm{mg} / \mathrm{L}$ in T. mentagrophytes ATCC 1148, T. rubrum ATCC MYA-4438, and T. rubrum ATCC 28189, respectively ( $\mathrm{p}<0.001$ ) (Figure 3C).

\section{Effect of Photodynamic Therapy on Planktonic Cells and on Early-Stage and Mature Biofilms}

The photodynamic therapy assay was applied using 2-chalcone as a photosensitizer against planktonic cells $\left(10^{6}\right.$ cells $\left./ \mathrm{mL}\right)$ and against early-stage and mature biofilms of the strains T. rubrum ATCC 28189, T. mentagrophytes ATCC 11481, and T. rubrum ATCC MYA-4438. The use of 2-chalcone as a photosensitizer for PDT was found to be effective against dermatophytes (Figure 4). The metabolic activities of planktonic cells of all tested species were inhibited from the concentration of $2 \mathrm{mg} / \mathrm{L}$ (Figure 4A), corresponding to a four-times reduction in concentration compared to its effect in the dark. The same reduction was observed in early-stage biofilms with inhibition from $4 \mathrm{mg} / \mathrm{L}$ (Figure 4B) and in mature biofilms with inhibition from $7.8 \mathrm{mg} /$ L (Figure 4C).

\section{Scanning Electron Microscopy of Biofilms Treated With 2-Chalcone in the Dark and Mediated PDT}

SEM was used to evaluate the damage to in vitro early-stage and mature biofilms treated with 2-chalcone. For this analysis, the concentrations of 2-chalcone (in the dark and irradiated) determined in the susceptibility test were used. The topographies of biofilms treated with 2-chalcone confirmed the findings of the XTT reduction assay and showed a total collapse in the hyphal cell wall probably due to leakage of cytoplasmic content. These damages were observed in both early-stage biofilms (Figure 5A) and mature biofilms (Figure 5B). Further, evident inhibition of biofilm maturation and decreased presence of polysaccharide material was observed in the initial biofilms. On the contrary, untreated biofilms showed a dense network of interconnected hyphae embedded in an extracellular matrix [Figures 5A (e) B (a, c, e)].

Photomicrographs of T. rubrum ATCC 28189 biofilms treated with 2-chalcone-mediated PDT (Figure 6) also confirmed the XTT assay findings. However, the biofilms were less dense, and the collapse of the hyphae cell walls was less prominent (Figures 6C, D). Biofilms treated at a dose of 150 $\mathrm{J} . \mathrm{cm}^{-2}$ without the photosensitizer (Figures 6A, B) showed similar results to those without treatment in the dark, also corroborating the XTT assay results.

TABLE 1 | Antifungal activity (expressed in mg/L) of 2-chalcone, terbinafine, and fluconazole against dermatophyte species.

\begin{tabular}{|c|c|c|c|c|c|c|}
\hline & \multicolumn{2}{|c|}{ T. rubrum ATCC 28189} & \multicolumn{2}{|c|}{ T. rubrum ATCC MYA-4438 } & \multicolumn{2}{|c|}{ T. mentagrophytes ATCC 11481} \\
\hline & MIC & MFC & MIC & MFC & MIC & MFC \\
\hline 2-Chalcone & 7.8 & 15.6 & 7.8 & 15.6 & 7.8 & 15.6 \\
\hline TRB & 0.03 & 0.06 & 0.03 & 0.06 & 0.008 & 0.016 \\
\hline FCZ & 64 & $>64$ & 4 & 32 & 1 & 16 \\
\hline
\end{tabular}

TRB, terbinafine; FCZ, fluconazole; MIC, minimum inhibitory concentration; MFC, minimum fungicidal concentration. 


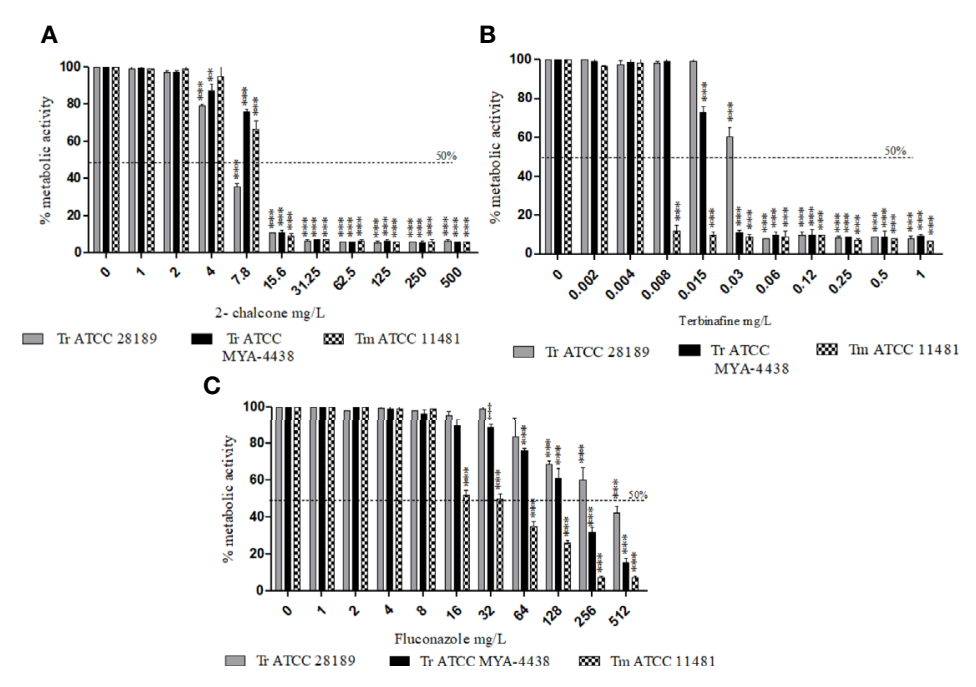

FIGURE 1 | Effect of 2-chalcone (A), terbinafine (B), and fluconazole (C) on early-stage biofilms of T. rubrum ATCC 28189, T. rubrum ATCC MYA-4438, and T. mentagrophytes ATCC 11481 measured using the XTT reduction assay. The compounds 2-chalcone and terbinafine inhibited the metabolic activity of early-stage biofilms from the concentrations of 15.6 and $32 \mathrm{mg} / \mathrm{L}$ in all strains tested. Biofilms formed by both the T. rubrum strains conferred resistance to fluconazole at all concentrations tested. Biofilms of the T. mentagrophytes strain were inhibited from the concentration of $64 \mathrm{mg} / \mathrm{L}\left({ }^{\star \star} \mathrm{p}<0.01 ;{ }^{\star \star \star} \mathrm{p}<0.001\right)$. Tr, T. rubrum; Tm, T. mentagrophytes.

\section{Cytotoxicity Assay With 2-Chalcone in HaCat}

Treatment of keratinocytes with 2-chalcone in the dark, reduced viability by almost $50 \%$ at $125 \mathrm{mg} / \mathrm{L}$ compared to the control without treatment (Figure 7). Cells treated with 2-chalconemediated PDT showed high toxicity with only $3 \%$ viability at the same concentration. After calculating the SI, 2-chalconemediated PDT presented better values in planktonic cells

\section{A}

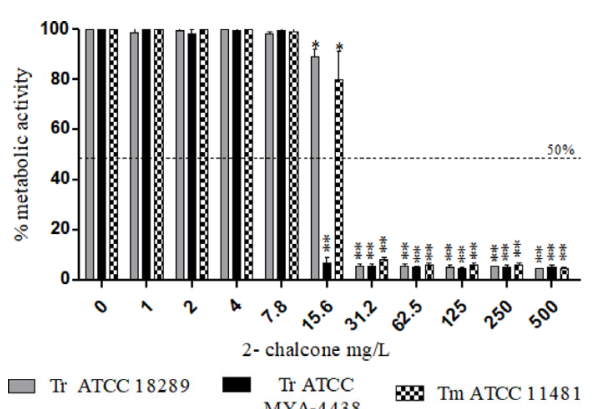

B

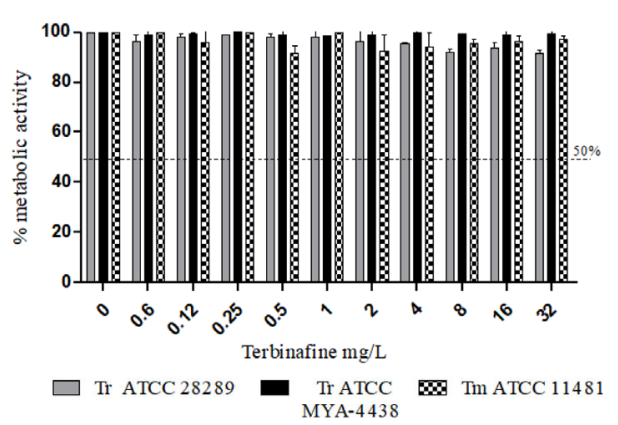

C

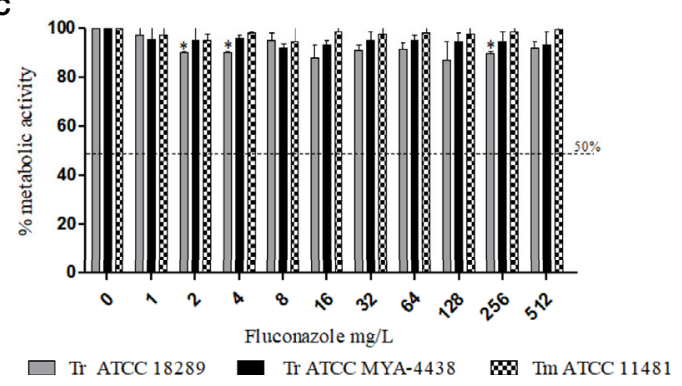

FIGURE 2 | Effect of 2-chalcone (A), terbinafine (B), and fluconazole (C) on mature biofims of T. rubrum ATCC 28189, T. rubrum ATCC MYA-4438, and T. mentagrophytes ATCC 11481 measured by the XTT reduction assay. Only 2-chalcone showed action against mature biofilms from a concentration of $31.2 \mathrm{mg} / \mathrm{L}$. On the contrary, biofilms formed by all tested strains were resistant to the drugs terbinafine and fluconazole even at the highest concentrations ( $\left.{ }^{*} \mathrm{p}<0.05 ;{ }^{* *} \mathrm{p}<0.001\right)$. Tr- T. rubrum, TmT. mentagrophytes. 

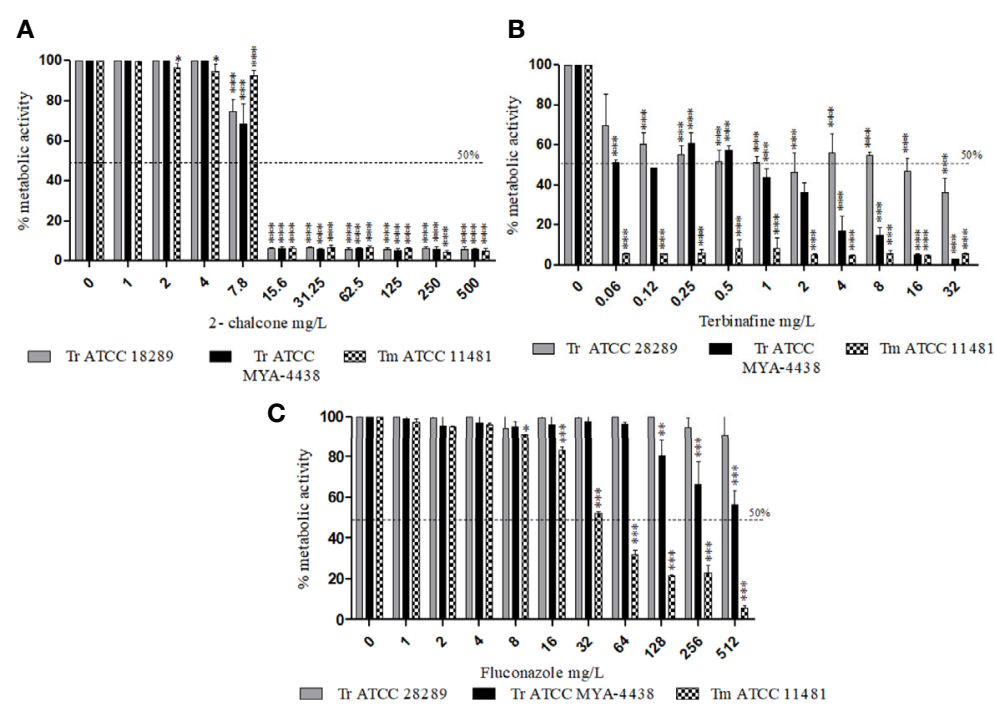

FIGURE 3 | Effect of 2-chalcone (A), terbinafine (B), and fluconazole (C) on planktonic cells of T. rubrum ATCC 28189, T. rubrum ATCC MYA-4438, and T. mentagrophytes ATCC 11481 measured using the XTT reduction assay. The compounds 2-chalcone and terbinafine were more potent against planktonic cells than fluconazole. The compounds 2-chalcone, terbinafine, and fluconazole inhibited the cellular metabolic activity in the planktonic form at the concentration used for biofilm formation $\left(10^{6} \mathrm{cell} / \mathrm{s} / \mathrm{mL}\right.$ ) of all strains tested, from the concentration of $15.6,0.06$, and $512 \mathrm{mg} / \mathrm{L}$ respectively. $\left({ }^{*} \mathrm{p}<0.05 ;{ }^{* *} \mathrm{p}<0.01 ;{ }^{* * *} \mathrm{p}<0.001\right)$. Tr, T. rubrum, Tm- T. mentagrophytes.

A

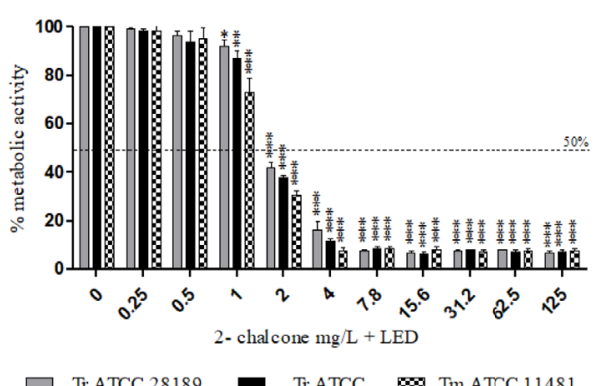

$\square \operatorname{Tr}$ ATCC 28189
B

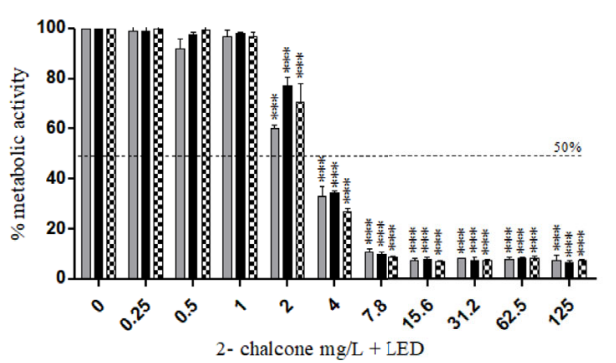

$\square \operatorname{Tr} \operatorname{ATCC} 28189$

- $\operatorname{Tr}$ ATCC $\$$ Tm ATCC 11481

C

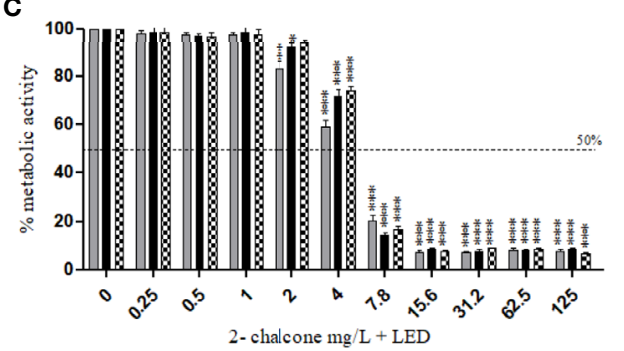

$\square$ Tr ATCC 28189

Tr ATCC MYA-4438

\$ Tin ATCC 11481

FIGURE 4 | Effect of 2-chalcone-mediated PDT using LED irradiation at a dose of $150 \mathrm{~J} / \mathrm{cm}^{2}$ in planktonic cells (10 ${ }^{6}$ cell/mL) (A), early-stage (B), and mature biofilms (C) of T. rubrum ATCC 28189, T. mentagrophytes ATCC 11481, and T. rubrum ATCC MYA-4438, measured by the XTT reduction assay. Potentiation of 2-chalcone was shown when it was mediated PDT resulting in the inhibition of planktonic forms and biofilms (early-stage and mature) from 2 , 4 , and 7.8 mg/L. $\left({ }^{*} \mathrm{p}<0.05 ;{ }^{* \star} \mathrm{p}<0.01 ;{ }^{* * *} \mathrm{p}<0.001\right)$. 
A

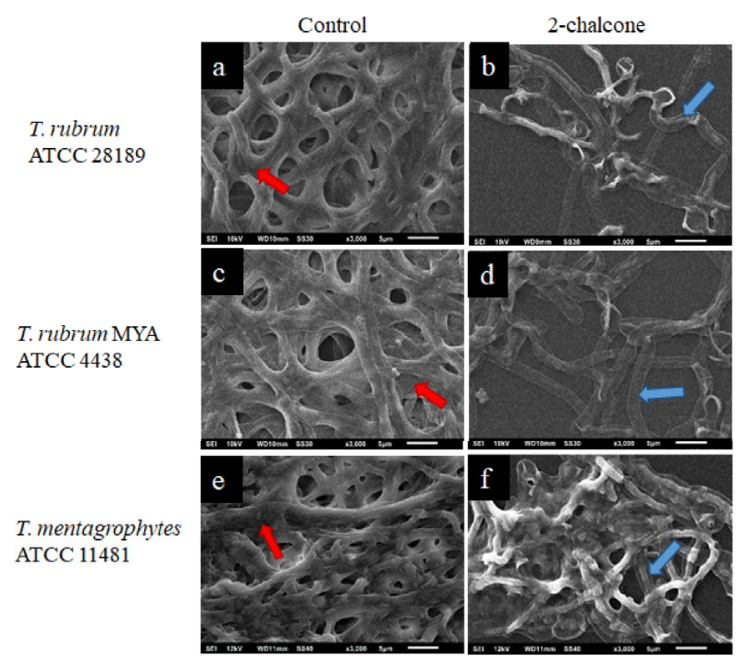

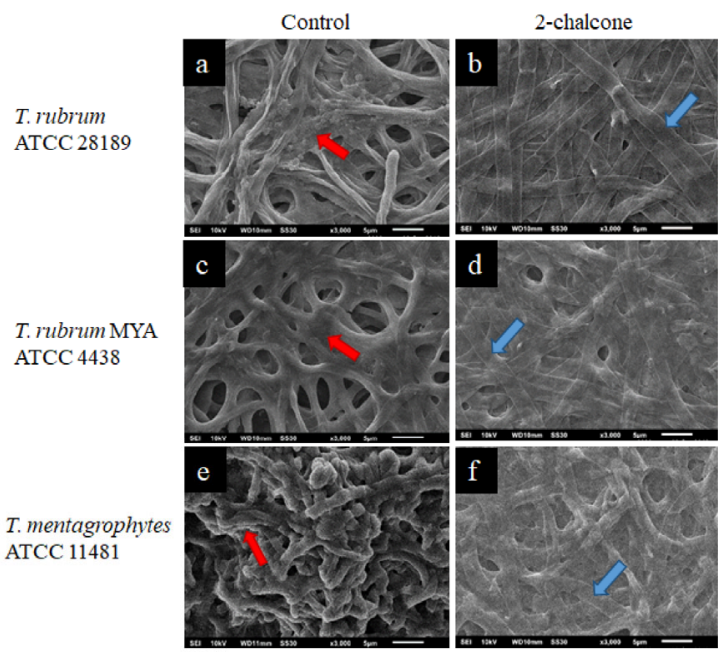

FIGURE 5 | Scanning electron microscopy (SEM) images of early stage (A) and mature biofilms (B) of T. rubrum ATCC 28189, T. rubrum ATCC MYA-4438, and T. mentagrophytes ATCC 11481 untreated ( $\mathrm{a}, \mathrm{c}, \mathrm{e})$ and treated with 2-chalcone in the dark (b, d, f). The images of untreated biofilms show a robust biofilm, formed with the entanglement of integral hyphae and covered with a polymeric extracellular matrix (red arrows). Biofilms treated in the early-stage with 2-chalcone present a low density showing the action of 2-chalcone in inhibiting their maturation. In mature biofilms, as in the early-stage biofilms, 2-chalcone promoted total hyphal collapse (blue arrows).
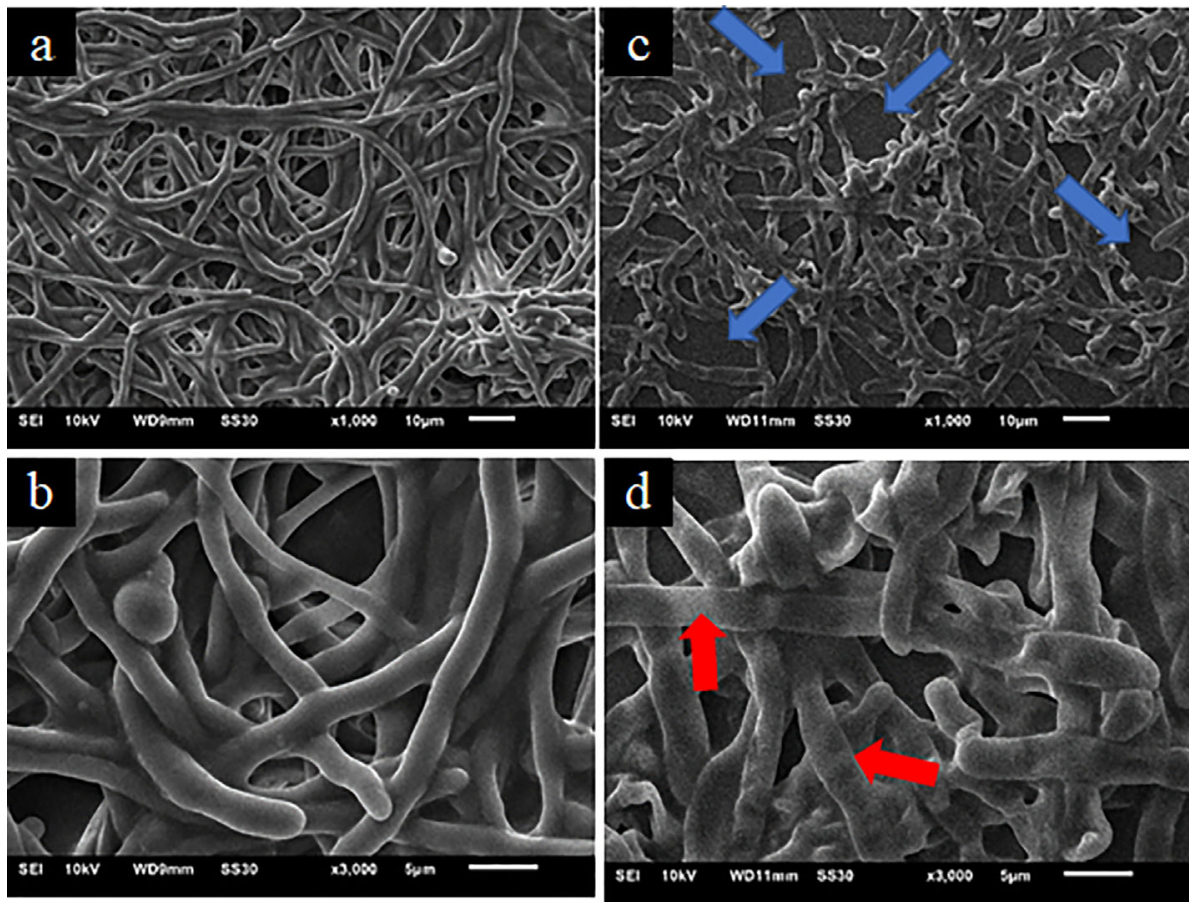

FIGURE 6 | Scanning electron microscopy images of mature T. rubrum ATCC 28189 biofilms treated with 2-chalcone combined with blue LED at a dose of 150 $\mathrm{J} / \mathrm{cm}^{2}$ (C, D) and irradiated only at a dose of $150 \mathrm{~J} / \mathrm{cm}^{2}$ without the photosensitizer (A, B). The blue arrows indicate empty spaces within the biofilm showing that the biofilm had become less dense. The red arrows show collapsed hyphae. 


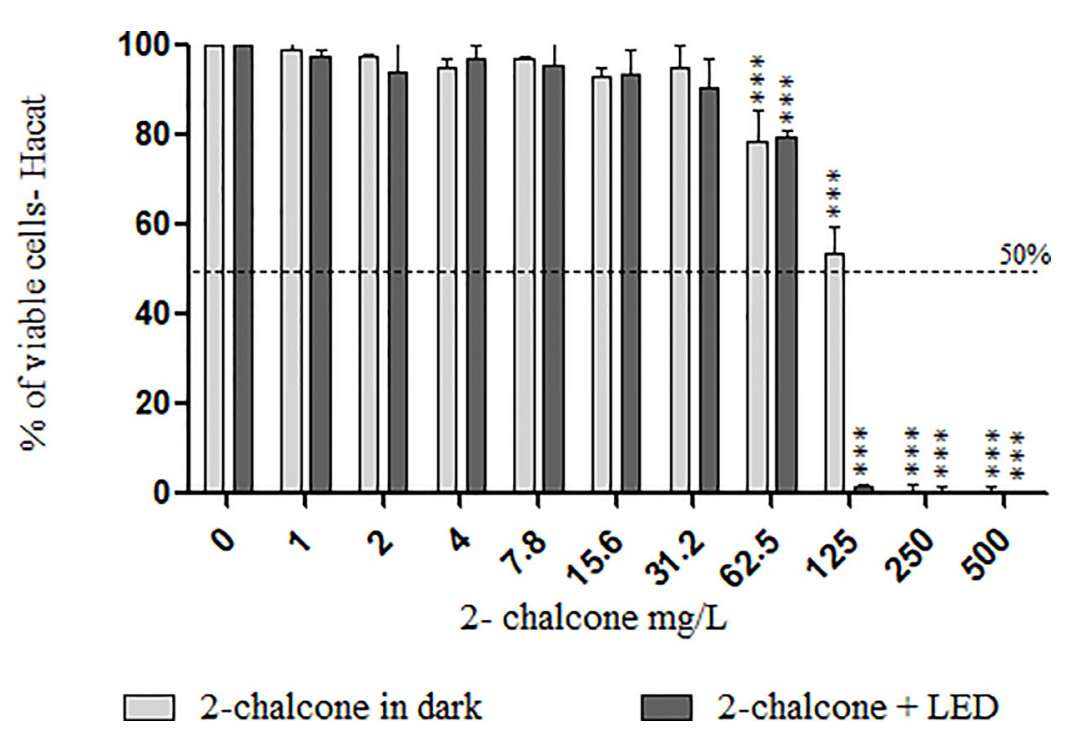

FIGURE 7 | Viability of HaCat cells measured using the resazurin reduction method after contact with different concentrations of 2-chalcone in the dark and 2-chalcone photoexcited with blue LED at a dose of $150 \mathrm{~J} / \mathrm{cm}^{2}$. The compound 2-chalcone decreased viability in PDT reducing the cell viability to $80 \%$ at a concentration of $62.5 \mathrm{mg} / \mathrm{L}$ when compared to the control without treatment. On the contrary, cells treated with 2-chalcone in the dark had viability greater than $50 \%$, even at concentrations of $125 \mathrm{mg} / \mathrm{L}\left({ }^{\star * \star} \mathrm{p}<0.001\right)$

(38.72) than in the mature biofilm (9.92) when compared to the 2-chalcone treatment in the dark (Table 2). Photoexcitation of the compound using a light source is promising as photosensitization resulted in significant potentiation and decreased cell toxicity.

\section{Determination of the Mechanisms of Action \\ Verification of Damage to the Cell Membrane and Wall}

The results of ergosterol quantification in the fungal membrane (Figure 8A) showed that 2-chalcone in the dark, as well as 2chalcone-mediated PDT, reduced the amount of total sterols extracted compared to the control $(\mathrm{p}<0.01)$. These findings revealed that ergosterol inhibition might be a mechanism of action for 2-chalcone. FLZ and AMB also reduced the number of sterols extracted from the membrane $(p<0.001)$.

Confocal microscopy images (Figure 8B) of cells treated with 2-chalcone showed discontinuous staining of the cell wall and structural compromise compared to the control indicating that 2-chalcone can damage cell wall chitin and/or cellulose. Cells treated with FLZ showed no change in the cell walls of the conidia and hyphae.

\section{Quantification of ROS and Apoptosis/Necrosis}

In the dark, 2-chalcone induced ROS generation when compared to the control ( $\mathrm{p}<0.001$ ) (Figure 9); however, 2-chalconemediated PDT did not produce ROS. AMB and $\mathrm{H}_{2} \mathrm{O}_{2}$ also induced ROS formation when compared to the untreated control $(\mathrm{p}<0.001)$. In contrast, FLZ did not induce ROS formation (Figure 9).

Cells treated with 2-chalcone in the dark presented high necrosis levels $(53-56.5 \%)$ compared to death by apoptosis $(18.4-32.3 \%)(p<0.001)$ (Figure 10A). When 2-chalcone was excited by a light source, almost all cell death was found to be due to necrosis (Figure 10B). AMB caused death through both mechanisms, apoptosis $(\mathrm{p}<0.05)$ and necrosis $(\mathrm{p}<0.001)$. In contrast, most FLZ-treated cells remained alive because the $T$. rubrum ATCC 28189 strain was resistant to FLZ as shown in the susceptibility assay. However, a tendency of cellular death mainly by necrosis, was observed (Figure 10).

\section{DISCUSSION}

Extensive research has been conducted on new antidermatophyte drugs (Gupta; Foley; Versteeg, 2017b; Gnat;

TABLE 2 | Values of $\mathrm{IC}_{50}$ and selectivity index (SI) in HaCat cell monolayers treated with 2-chalcone in the dark and with photosensitization.

\begin{tabular}{|c|c|c|c|c|c|c|c|}
\hline \multirow[t]{2}{*}{ Condition } & \multirow[t]{2}{*}{$\mathrm{IC}_{50}$} & \multicolumn{3}{|c|}{$\mathrm{SI}\left(\mathrm{IC}_{50} / \mathrm{MIC}\right)$ planctonic $10^{6} \mathrm{cel} / \mathrm{mL}$} & \multicolumn{3}{|c|}{ SI (IC $\left.{ }_{50} / \mathrm{MIC}\right)$ mature biofilm } \\
\hline & & Tr ATCC 28189 & Tr ATCC MYA4438 & Tm ATCC 11481 & Tr ATCC 28189 & Tr ATCC MYA4438 & Tm ATCC 11481 \\
\hline 2-chalcone in dark & 130.7 & 16.75 & 8.38 & 8.38 & 4.18 & 8.36 & 4.18 \\
\hline 2-chalcone + LED (150 J/cm²) & 77.44 & 38.72 & 38.72 & 38.72 & 9.92 & 9.92 & 9.92 \\
\hline
\end{tabular}

$I_{50}$, concentration that promotes $50 \%$ inhibition of cellular activity. $\mathrm{Tr}$, T. rubrum; $\mathrm{Tm}, \mathrm{T}$. mentagrophytes. 
A
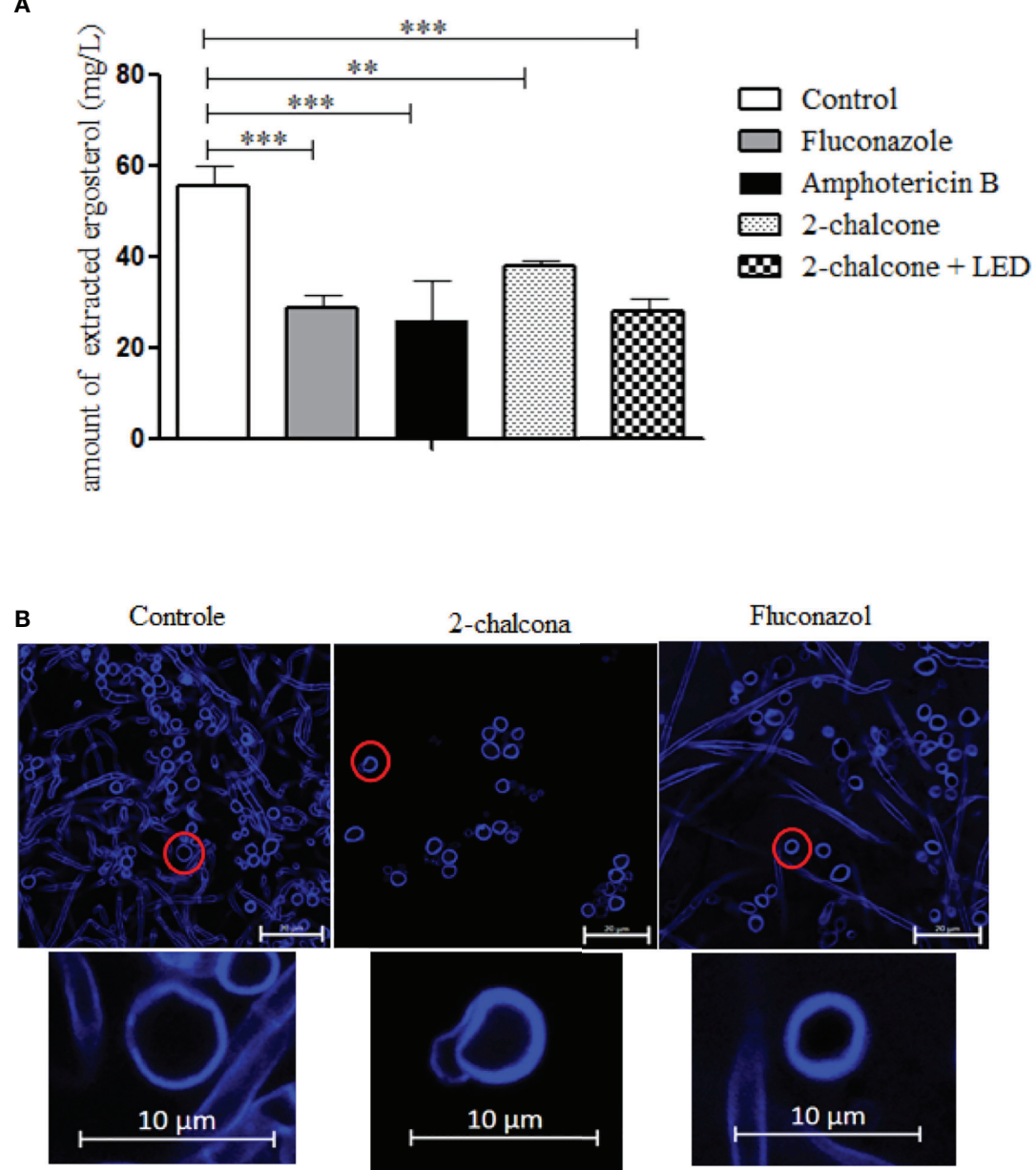

FIGURE 8 | The amount of extracted ergosterol (A) and confocal laser scanning microscopy images (CLSM) (B) of T. rubrum ATCC 28189 treated with 2-chalcone, fluconazole, and amphotericin B. The ergosterol quantification graph shows that treatments with 2-chalcone in the dark and 2-chalcone-mediated PDT reduced the amount of sterols extracted, suggesting that this molecule may have an action on ergosterol or its synthesis chain. Amphotericin B and fluconazole also reduced the amount of steroids extracted, proving their direct action and on the synthesis chain, respectively. In CLSM images, the cell wall is stained with calcofluor white. Cells treated with 2-chalcone showed changes in the cell wall with compromised structure. However, cells treated with fluconazole showed cell wall integrity. ${ }^{* *} \mathrm{p}<0.01$; ${ }^{* \star *} \mathrm{p}<0.001$.

Lagowski; Nowakiewicz, 2020; Iwanaga et al., 2020) as microorganisms are increasingly developing resistance to conventional drugs with the hypothetical formation of biofilms in onychomycosis and high rates of recurrence and reinfection (Gupta; Daigle; Carviel, 2016; Gupta; Foley, 2019). Further, the increasing human infections by zoophilic species, mainly in tinea capitis and tinea unguium, are generally more challenging to treat and require systemic treatment (Gnat; Lagowski; Nowakiewicz, 2020).

The present work showed the anti-dermatophyte and anti-biofilm action of a compound derived from chalcone, a molecule of natural origin that is abundant in fruits and vegetables and has relatively simple laboratory synthesis. The compound shows enhanced action mediated PDT, with a better SI in human keratinocytes in the context of its effect in the dark. Tests of susceptibility and MFC determination showed the potent action of 2-chalcone with a MIC of
$7.8 \mathrm{mg} / \mathrm{L}$ in all tested strains. Although the action of chalcones varies widely with their structural replacement pattern, natural and synthetic chalcones have already shown antifungal activity against Candida spp (Tavares et al., 2011), Cryptococcus gattii (Palanco et al., 2017), Paracoccidioides brasiliensis (Medina-Alarcón et al., 2020), H. capsulatum (Melo et al., 2017), and against dermatophytes (López et al., 2001; Gupta; Jain, 2015), proving to be potential candidates as future antifungal drugs. The MFC is defined as the lowest concentration of the drug necessary to inhibit $99.9 \%$ of fungal growth (Gil-Alonso et al., 2019). Hazen (1998) considered an antifungal agent as fungicidal if the MIC and MFC relationship is not greater than four times. In all tested strains, 2-chalcone presented a potent fungicidal profile, with the relation between MIC and MFC equal to 2 times. The TRB and FLZ susceptibility of all strains corroborated with previous studies conducted by Costa-Orlandi et al. (2020). 


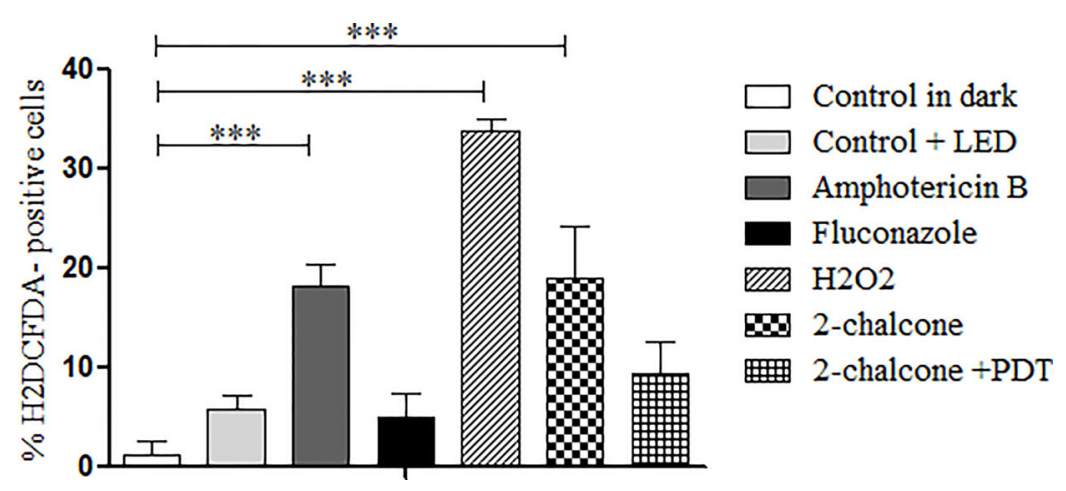

FIGURE 9 | Measurement of ROS production after treatment of T. rubrum ATCC 28189 with 2-chalcone in the dark and mediated PDT (2-chalcone + LED). The compounds amphotericin B, hydrogen peroxide, and 2-chalcone in the dark induced ROS formation when compared to the control without treatment in the dark. Treatment with 2-chalcone-mediated PDT did not induce ROS formation when compared to the control + LED. ${ }^{\star \star \star} p<0.001$.

A

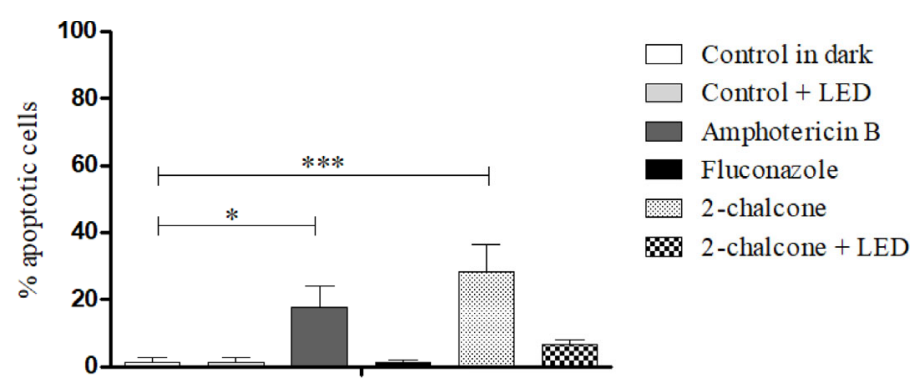

B
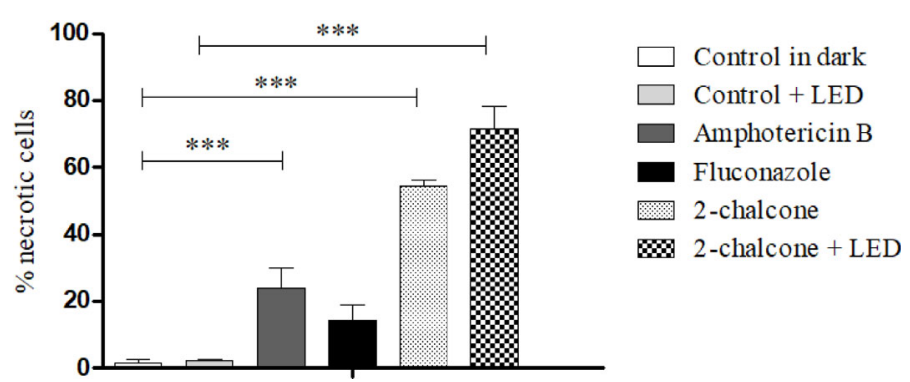

FIGURE 10 | Mechanism of death due to apoptosis (A) and necrosis (B) induced after treatment of T. rubrum ATCC 28189 with 2-chalcone in the dark and with 2-chalcone mediated PDT (2-chalcone +LED), compared with the untreated control. Further, 2-chalcone in the dark and amphotericin B induced cell death by both apoptosis and necrosis, whereas 2-chalcone +LED only induced death by necrosis. ${ }^{\star} p<0.05 ;{ }^{* \star} \mathrm{p}<0.001$.

Further, 2-chalcone also showed potent action against earlystage and mature biofilms, as well as the planktonic form with $10^{6}$ cells/mL with variations of only two dilutions. Costa-Orlandi et al. (2020) and Singulani et al. (2018) considered insignificant variations in dilutions up to two dilutions. These results are encouraging as no effect was observed with the drugs TRB and
FLZ, mainly when used to treat mature biofilms. Some studies conducted by our group have already demonstrated the antibiofilm activity of chalcones against fungal species such as $C$. gattii (Palanco et al., 2017) and H. capsulatum (Melo et al., 2017). Studies have been carried out to assess the anti-biofilm action of conventional drugs for treating dermatophytoses such as TRB, 
FLZ (Costa-Orlandi et al., 2020), itraconazole, voriconazole, griseofulvin (Brilhante et al., 2018), econazole (Toukabri et al., 2018), and formulations of piroctone-based shampoos (Santos; Dias-Souza, 2017). However, in most cases, 50 times the MIC is required to observe any biofilm inhibition (Brilhante et al., 2018). Planktonic forms $\left(10^{6}\right.$ cells $\left./ \mathrm{mL}\right)$ are more sensitive to drugs when compared to biofilms, confirming that these communities show increased resistance to conventional antifungals. The strain T. rubrum ATCC 28189 demonstrated resistance to FLZ even in the planktonic form as described previously (Costa-Orlandi et al., 2020).

PDT is a relatively affordable treatment when used as an inexpensive photosensitizer and can be implemented in hospitals without incurring high costs (Bacellar et al., 2015). Some studies have shown the fungicidal effect of photodynamic therapy against T. rubrum and T. mentagrophytes using $\mathrm{CO}_{2}$ (De Oliveira et al., 2015) and toluidine (Baltazar et al., 2013), as well as with hypericin, hypocrillin, and curcumin as photosensitizers against Candida spp. (Davies et al., 2016; Yang et al., 2019). Cyclic chalcones have significant characteristics for effects in PDT (Melo et al., 2017). However, the photosensitizing properties of chalcones can be easily lost by the modification of their structures. For instance, Zhuang et al. (2018) reported that the introduction of a methyl group at the $\alpha$ position of the unsaturated ketone resulted in the loss of fluorescence. The usage of 2-chalcone as a photosensitizer in PDT showed that the compound did not lose its photosensitizing properties. Further, its effect was enhanced compared to that in the dark with a reduction in the MIC to a fourth part against planktonic cells, early-stage and mature biofilms.

Photosensitization with 2-chalcone showed increased toxicity in HaCat cells, with an $\mathrm{IC}_{50}$ reduction by almost by half. Similar results have been reported by Melo et al. (2017) when irradiated chalcone derivatives were co-incubated with NOK, HepG2, and $\mathrm{HaCat}$ cell lines at a dose of 12 and $42 \mathrm{~J}_{\mathrm{cm}} \mathrm{cm}^{-2}$. The researchers also found that the dose of light was directly proportional to the increase in cell toxicity. In contrast, the SI in the treatment of 2chalcone-mediated PDT was higher than that in the dark treatment. The SI is the ratio of the $\mathrm{IC}_{50}$ and MIC (Scorzoni et al., 2016). This index indicates a compound's selectivity between a fungal and host cell, to evaluate the relationship between safety and potency (Bagla et al., 2014; Scorzoni et al., 2016). SI values higher than ten are considered more specific (Ochoa-Pacheco et al., 2017; Singulani et al., 2019). Treatment of 2-chalcone-mediated PDT proved to be safer, with SI values ranging from 9.92 to 38.72 in mature biofilms and planktonic forms, respectively. These results are a consequence of the decreased MIC values in planktonic cells and biofilms, and the reduced toxicity in $\mathrm{HaCat}$ cells.

The antifungal properties of chalcones depend on their structural replacement pattern, as well as on the fungal genotype and cell density (López et al., 2001; Illicachi et al., 2017). The action on the biosynthesis of $\beta$ - $(1,3)$ glucan and chitin of the fungal cell wall (Gupta; Jain, 2015; Illicachi et al., 2017) has already been demonstrated, also the inhibition of the glutathione-S-transferase (GST) family, that are enzymes involved in drug resistance (Illicachi et al., 2017). Due to the diversity of mechanisms underlying the action of chalcones, our work verified the integrity of structures such as cell walls and cell membranes as well as the functional imbalance including oxidative stress induction and cell death mechanism in the treated samples. Treatment with 2-chalcone in the dark and 2-chalcone-mediated PDT reduced membrane ergosterol contents. The action of chalcones on this molecule has not been reported so far. Lack of ergosterol alters membrane fluidity, causing an increase in permeability and consequent osmotic imbalance (Ouf et al., 2013). Cells treated with AMB and FLZ also showed lower amounts of ergosterol because these drugs act by binding directly to membrane ergosterol and inhibiting its synthesis, respectively (Singulani et al., 2019). Further, our results showed deformation of the cell wall structure when stained with calcofluor white, a nonspecific fluorophore that binds cellulose and chitin mainly in beta 1-3 and beta 1-4 polysaccharides, and emit fluorescence when excited (Harrington; Hageage, 2003). The action of chalcones on the fungal cell wall has been reported previously (Gupta; Jain, 2015; Illicachi et al., 2017). Reduced ergosterol and impaired cell wall structure confirm the findings in the SEM images showing that the hyphae were fully collapsed with a "pressed cell" appearance.

Treatment with 2-chalcone in the dark induced significant ROS generation. Drugs such as amphotericin B have ROS induction as a secondary mechanism of action, in addition to the main mechanism via ergosterol (Singulani et al., 2019). ROS generation depends on the drug's ability to reach the intracellular region (Yoo; Ha, 2012). Possibly, a part of the compound that reached the cytoplasm was responsible for ROS generation. However, a significant part acts on the cell wall and membrane. Treatment with $\mathrm{AMB}$ as well as $\mathrm{H}_{2} \mathrm{O}_{2}$ induced ROS production. Further, AMB caused death by apoptosis as well as necrosis. Similar results were reported by Singulani et al. (2019) in C. neoformans. The presence of oxygen in the PDT takes the photosensitizer to an excited state with high reactivity, facilitating interactions with the surrounding molecules (Kwiathowski et al., 2018; Donohoe et al., 2019). These interactions can be type I or type II. Type I interactions result in free radicals whereas type II interactions induce formation of ROS such as singlet oxygen $\left({ }^{1} \mathrm{O}_{2}\right)$, superoxide, hydrogen peroxide, and hydroxyl radical (Shibu et al., 2013; Zhang et al., 2018a). Our results showed that 2-chalcone mediated PDT promoted low ROS induction. Considering these facts, we speculate that the photosensitized 2-chalcone probably induces free radicals, through type I reactions.

Apoptosis and necrosis are the main mechanisms of cell death in cytotoxic responses to PDT. These depend on the photosensitizer nature, light dose, and cell type (Yoo; Ha, 2012). Treatment with 2-chalcone-mediated PDT almost entirely induced fungal death by necrosis. Necrosis is usually associated with a high concentration of photosensitizer and/or light dose, severe cell damage, and photosensitizers with tropism to the cell membrane (Yoo; Ha, 2012). A relatively high dose (150 $\mathrm{J} . \mathrm{cm}^{-2}$ ) was used in our assays, and the results showed that 2chalcone has a tropism for the fungal membrane and cell wall. Induction of apoptotic death by the compound in the dark is probably a consequence of ROS generation. However, most cells 
died from necrosis, which may be a result of other cell targets such as the cell wall and the fungal membrane ergosterol.

\section{CONCLUSION}

Our results showed that 2-chalcone is a molecule with antidermatophyte and anti-biofilm properties. When mediated PDT, its effect is enhanced, causing low toxicity to human skin keratinocytes and high SI value. Further, the compound targets specific fungal structures and promotes ROS generation, resulting in cell death from apoptosis and necrosis. Overall, this study contributes significantly to the discovery of new compounds with anti-biofilm activity, and other studies are being conducted to prove these findings both ex vivo and in vivo.

\section{DATA AVAILABILITY STATEMENT}

The original contributions presented in the study are included in the article/supplementary material. Further inquiries can be directed to the corresponding author.

\section{REFERENCES}

Aggarwal, N., and Goindi, S. (2012). Preparation and Evaluation of Antifungal Efficacy of Griseofulvin Loaded Deformable Membrane Vesicles in Optimized Guinea Pig Model of Microsporum Canis - Dermatophytosis. Int. J. Pharm. 437 (1-2), 277-287. doi: 10.1016/j.ijpharm.2012.08.015

Aggarwal, R., Targhotra, M., Kumar, B., Sahoo, P. K., and Chauhan, M. K. (2020). Treatment and Management Strategies of Onychomycosis. J. Mycol. Med. 30 (100949), 1-15. doi: 10.1016/j.mycmed.2020.100949

Aneke, C., Otranto, D., and Cafarchia, C. (2018). Therapy and Antifungal Susceptibility Profile of Microsporum Canis. J. Fungi 4 (107), 1-14. doi: 10.3390/jof4030107

Arthington-skaggs, B. A., Jradi, H., Desai, T., and Morrison, C. J. (1999). Quantitation of Ergosterol Content : Novel Method for Determination of Fluconazole Susceptibility of Candida Albicans. J. Clin. Diagn. Res. 37 (10), 3332-3337. doi: 10.1128/JCM.37.10.3332-3337

Bacellar, I. O. L., Tsubone, T. M., Pavani, C., and Baptista, M. S. (2015). Photodynamic Efficiency : From Molecular Photochemistry to Cell Death. Int. J. Mol. Sci. 16, 20523-20559. doi: 10.3390/ijms160920523

Bagla, V. P., Mcgaw, L. J., Elgorashi, E. E., and Eloff, J. N. (2014). Antimicrobial Activity, Toxicity and Selectivity Index of Two Biflavonoids and a Flavone Isolated From Podocarpus Henkelii (Podocarpaceae) Leaves. Bio Med. Cent Complement Altern. Med. 14 (383), 2-7. doi: 10.1186/1472-6882-14-383

Baltazar, L. M., Soares, B. M., Carneiro, H. C. S., Avila, T. V., Ferreira, L., Gouveia, L. F., et al. (2013). Photodynamic Inhibition of Trichophyton Rubrum: in Vitro Activity and the Role of Oxidative and Nitrosative Bursts in Fungal Death. J. Antimicrob. Chemother. 68, 354-361. doi: 10.1093/jac/dks414

Brilhante, R. S. N., Correia, E. E. M., Guedes GM de, M., de Oliveira, J. S., CasteloBranco D de, S. C. M., Cordeiro R de, A., et al. (2018). in Vitro Activity of Azole Derivatives and Griseofulvin Against Planktonic and Biofilm Growth of Clinical Isolates of Dermatophytes. Mycoses. 61 (7), 449-454. doi: 10.1111/ myc. 12763

Burkhart, C. N., Burkhart, C. G., and Gupta, A. K. (2002). Dermatophytoma: Recalcitrance to Treatment Because of Existence of Fungal Biofilm. J. Am. Acad. Dermatol. 47 (4), 629-631. doi: 10.1067/mjd.2002.124699

Cai, C. Y., Rao, L., Rao, Y., Guo, J. X., Xiao, Z. Z., Cao, J. Y., et al. (2017). Analogues of Xanthones-Chalcones and Bis-Chalcones as Alpha-Glucosidase Inhibitors and Anti-Diabetes Candidates. Eur. J. Med. Chem. 130, 51-59. doi: 10.1016/ j.ejmech.2017.02.007

\section{AUTHOR CONTRIBUTIONS}

$\mathrm{NB}, \mathrm{CC}-\mathrm{O}, \mathrm{CF}$, and MM-G conceived and designed the study. $\mathrm{NB}, \mathrm{CC}-\mathrm{O}, \mathrm{CV}$, and JB performed all the experiments. NB, CV, and CC-O analyzed the data and wrote the manuscript. LA and LR synthesized 2-chalcone. All authors contributed to the article and approved the submitted version.

\section{FUNDING}

This work was supported by Fundação de Amparo à Pesquisa do Estado de São Paulo-FAPESP [2019/22188-8 (NB), 2018/027859 (MM-G), 2017/18388-6 (CC-O), 2020/15586-4 (CV)], Programa de Apoio ao Desenvolvimento Científico (PADC) da Faculdade de Ciências Farmacêuticas da UNESP, Coordenação de Aperfeiçoamento de Pessoal de Nivel Superior (CAPES) [Finance code 001; 88887.500765/2020-00 (CV)], Conselho Nacional de Desenvolvimento Científico e Tecnológico (CNPq) [142049/2019- 0 (NB), 105072/2018-4 (JB), 134559/2018-5 (CV)], and Instituto de Bolsa de Estudos (IBE) - Moçambique [IBE150/2017 (NB)].

Clinical and Laboratory Standards Institute (CLSI) (2008). Reference Method for Broth Dilution Antifungal Susceptibility Testing of Filamentous Fungi 22, M38-MA2.

Costa-Orlandi, C., Sardi, J., Pitangui, N., de Oliveira, H., Scorzoni, L., Galeane, M., et al. (2017). Fungal Biofilms and Polymicrobial Diseases. J. Fungi 3 (2), 22. doi: 10.3390/jof3020022

Costa-Orlandi, C. B., Sardi, J. C. O., Santos, C. T., Fusco-Almeida, A. M., and Mendes, M. (2014). in Vitro Characterization of Trichophyton Rubrum and T. mentagrophytes biofilms Biofouling 30 (6), 719-727. doi: 10.1080/ 08927014.2014 .919282

Costa-Orlandi, C. B., Serafim-Pinto, A., Silva, P. B., Lacorte Singulani, J. D., Santos, C. T., Nazaré, A. C., et al. (2020). Incorporation of Nonyl Nanostructured Lipid Systems : Effective Alternative for Maintaining Anti-Dermatophytic and Antibiofilm Activities and Reducing Toxicity At High Concentrations. Front. Microbiol. 11:1154. doi: 10.3389/fmicb.2020.01154

Curcio, J. S., Silva, M. G., Bailao MG da, S., Báo, S. N., Caseletti, L., Bailão, A. M., et al. (2017). Identification of Membrane Proteome of Paracoccidioides Lutzii and Its Regulation by Zinc. Futur. Sci. 3 (4), 1-17. doi: 10.4155/fsoa2017-0044

Danielli, L. J., Lopes, W., Vainstein, M. H., Fuentefria, A. M., and Apel, M. A. (2017). Biofilm Formation by Microsporum Canis. Clin. Microbiol. Infect. 23 (12), 941-942. doi: 10.1016/j.cmi.2017.06.006

Davies, A., Gebremedhin, S., Yee, M., Padilla, R. J., Duzgunes, N., Konopka, K., et al. (2016). Cationic Porphyrin-Mediated Photodynamic Inactivation. J. Physiol. Pharmacol. 67 (5), 777-783.

De Figueiredo Freitas, L. S., Rossoni, R. D., Jorge, A. O. C., and Junqueira, J. C. (2017). Repeated Applications of Photodynamic Therapy on Candida Glabrata Biofilms Formed in Acrylic Resin Polymerized. Lasers Med. Sci. 32 (3), 549 555. doi: 10.1007/s10103-017-2147-4

De Hoog, G. S., Dukik, K., Monod, M., Packeu, A., and Stubbe, D. (2017). Toward a Novel Multilocus Phylogenetic Taxonomy for the Dermatophytes. Mycopathologia 182, 5-31. doi: 10.1007/s11046-016-0073-9

De Oliveira, G. B., Antonio, J. R., Antonio, C. R., and Tomé, F. A. (2015). the Association of Fractional CO2 Laser 10.600nm and Photodynamic Therapy in the Treatment of Onychomycosis. Bras. Dermatol. 90 (4), 468-471. doi: 10.1590/abd1806-4841.20153588

Donohoe, C., Senge, M. O., Arnaut, L. G., and Gomes-da-Silva, L. C. (2019). Cell Death in Photodynamic Therapy: From Oxidative Stress to Anti-Tumor 
Immunity. Biochim. Biophys. Acta Rev. Cancer 1872 (2), 188308. doi: 10.1016/ j.bbcan.2019.07.003

Faway, E., Cambier, L., Mignon, B., Poumay, Y., and Rouvroit, C. L. De. (2016). Modeling Dermatophytosis in Reconstructed Human Epidermis : A New Tool to Study Infection Mechanisms and to Test Antifungal Agents. Med. Mycol J. 0 (0), 1-10. doi: 10.1093/mmy/myw111

Fu, D. J., Zhang, S. Y., Liu, Y. C., Zhang, L., Liu, J. J., Song, J., et al. (2016). Design, Synthesis and Antiproliferative Activity Studies of Novel DithiocarbamateChalcone Derivates. Bioorganic Med. Chem. Lett. 26 (16), 3918-3922. doi: 10.1016/j.bmcl.2016.07.012

Garcia, L. M., Costa-Orlandi, C. B., Bila, N. M., Vaso, C. O., Gonçalves, L. N., Marisa, F.-A. A., et al. (2020). A Two-Way Road : Antagonistic Interaction Between Dual-Species Biofilms Formed by Candida Albicans/Candida Parapsilosis and Trichophyton Rubrum. Front. Microbiol. 11, 1980. doi: 10.3389/fmicb.2020.01980

Gil-Alonso, S., Quindós, G., Cantón, E., Eraso, E., and Jauregizar, N. (2019). Killing Kinetics of Anidulafungin, Caspofungin and Micafungin Against Candida Parapsilosis Species Complex: Evaluation of the Fungicidal Activity. Rev. Iberoam Micol 36 (1), 24-29. doi: 10.1016/j.riam.2018.12.001

Gnat, S., Łagowski, D., and Nowakiewicz, A. (2020). Major Challenges and Perspectives in the Diagnostics and Treatment of Dermatophyte Infections. J. Appl. Microbiol. 129 (2), 212-232. doi: 10.1111/jam.14611

Gupta, A. K., and Cooper, E. A. (2008). Update in Antifungal Therapy of Dermatophytosis. Mycopathologia 166 (5-6), 353-367. doi: 10.1007/s11046008-9109-0

Gupta, A. K., Daigle, D., and Carviel, J. L. (2016). the Role of Biofilms in Onychomycosis. J. Am. Acad. Dermatol. 74 (6), 1241-1246. doi: 10.1016/ j.jaad.2016.01.008

Gupta, A. K., and Foley, K. A. (2019). Evidence for Biofilms in Onychomycosis. G Ital Dermatol. Venereol 154 (1), 50-55. doi: 10.23736/S0392-0488.18.06001-7

Gupta, A. K., Foley, K. A., and Versteeg, S. G. (2017b). New Antifungal Agents and New Formulations Against Dermatophytes. Mycopathologia 182 (1-2), 127141. doi: $10.1007 / \mathrm{s} 11046-016-0045-0$

Gupta, D., and Jain, D. K. (2015). Chalcone Derivatives as Potential Antifungal Agents: Synthesis, and Antifungal Activity. J. Adv. Pharm. Technol. Res. 6 (3), 114-117. doi: 10.4103/2231-4040.161507

Gupta, A. K., Versteeg, S. G., and Shear, N. H. (2017a). Onychomycosis in the 21st Century: An Update on Diagnosis, Epidemiology, and Treatment. J. Cutan Med. Surg. 21 (6), 525-539. doi: 10.1177/1203475417716362

Harrington, B. J., and Hageage, G. J. (2003). Your Lab Focus Calcofluor White : A Review of Its Uses and Applications in Clinical Mycology and Parasitology. Lab. Med. 34 (5), 361-367. doi: 10.1309/EPH2TDT8335GH0R3

Hazen, K. C. (1998). Fungicidal Versus Fungistatic Activity of Terbinafine and Itraconazole: An in Vitro Comparison. J. Am. Acad. Dermatol. 38 (5 Pt 3), S37S41. doi: 10.1016/s0190-9622(98)70482-7

Heidrich, D., Garcia, M. R., Stopiglia, C. D., Magagnin, C. M., Daboit, T. C., Vetoratto, G., et al. (2015). Dermatophytosis: A 16-Year Retrospective Study in a Metropolitan Area in Southern Brazil. J. Infect. Dev. Ctries 9 (8), 865-871. doi: $10.3855 /$ jidc. 5479

Illicachi, L. A., Montalvo-Acosta, J. J., Insuasty, A., Quiroga, J., Abonia, R., Sortino, M., et al. (2017). Synthesis and DFT Calculations of Novel Vanillin-Chalcones and Their 3-Aryl-5-(4-(2-(Dimethylamino)- Ethoxy)-3-Methoxyphenyl)-4,5Dihydro-1H-Pyrazole-1-Carbaldehyde Derivatives as Antifungal Agents. Molecules. 22 (9):1476. doi: 10.3390/molecules22091476

Ivaskiene, M., Matusevicius, A. P., Grigonis, A., Zamokas, G., and Babickaite, L. (2016). Efficacy of Topical Therapy With Newly Developed Terbinafine and Econazole Formulations in the Treatment of Dermatophytosis in Cats. Pol. J. Vet. Sci. 19 (3), 535-543. doi: 10.1515/pjvs-2016-0067

Iwanaga, T., Ushigami, T., Anzawa, K., and Mochizuki, T. (2020). Viability of Pathogenic Dermatophytes During a 4-Week Treatment With 1\% Topical Luliconazole for Tinea Pedis. Med. Mycol. 58 (3), 401-403. doi: 10.1093/mmy/ myz056

Karimi-Sales, E., Mohaddes, G., and Alipour, M. R. (2017). Chalcones as Putative Hepatoprotective Agents: Preclinical Evidence and Molecular Mechanisms. Pharmacol. Res. 129, 177-187. doi: 10.1016/j.phrs.2017.11.022

Khanapure, S., Jagadale, M., Bansode, P., Choudhari, P., and Rashinkar, G. (2018). Anticancer Activity of Ruthenocenyl Chalcones and Their Molecular Docking Studies. J. Mol. Struct. 1173, 142-147. doi: 10.1016/j.molstruc.2018.06.091
Kotlyar, V. M., Kolomoitsev, O. O., Nikolaievskyi, D. V., Pedan, P. I., Chumak, A. Y., Orlov, V. D., et al. (2019). Photoreactive Fused Aziridinylpiperazines on the Background of 4-Substituted Chalcones and Their Benzimidazolic Analogs. J. Mol. Struct. 1180, 741-746. doi: 10.1016/j.molstruc.2018.12.015

Kwiatkowski, S., Knap, B., Przystupski, D., Saczko, J., Kędzierska, E., Knap-Czop, K., et al. (2018). J. Photodynamic Therapy - Mechanisms, Photosensitizers and Combinations. BioMed. Pharmacother 106, 1098-1107. doi: 10.1016/ j.biopha.2018.07.049

López, S. N., Castelli, M. V., Zacchino, S. A., Domínguez, J. N., Lobo, G., CharrisCharris, J., et al. (2001). in Vitro Antifungal Evaluation and Structure-Activity Relationships of a New Series of Chalcone Derivatives and Synthetic Analogues, With Inhibitory Properties Against Polymers of the Fungal Cell Wall. Bioorg Med. Chem. 9 (8), 1999-2013. doi: 10.1016/s0968-0896(01)00116-x

Mahboubi, M., HeidaryTabar, R., and Mahdizadeh, E. (2017). the AntiDermatophyte Activity of Zataria Multiflora Essential Oils. J. Mycol Med. 27 (2), 232-237. doi: 10.1016/j.mycmed.2017.03.001

Mahboubi, M., and Kazempour, N. (2015). the Anti-Dermatophyte Activity of Allium Hirtifolium Boiss Aqueous Extract. J. Mycol Med. 25 (1), e10-e14. doi: 10.1016/j.mycmed.2014.10.010

Mai, B., Gao, Y., Li, M., Wang, X., Zhang, K., Liu, Q., et al. (2017). Photodynamic Antimicrobial Chemotherapy For Staphylococcus Aureus and MultidrugResistant Bacterial Burn Infection in Vitro and in Vivo. Int. J. Nanomedicine 12, 5915-5931. doi: 10.2147/IJN.S138185

Makimura, K., Tamura, Y., Mochizuki, T., Hasegawa, A., Tajiri, Y., Hanazawa, R, et al. (1999). Phylogenetic Classification and Species Identification of Dermatophyte Strains Based on DNA Sequences of Nuclear Ribosomal Internal Transcribed Spacer 1 Regions. J. Clin. Microbiol. 37 (4), 920-924. doi: 10.1128/JCM.37.4.920-924

Maraki, S., and Mavromanolaki, V. E. (2016). Epidemiology of Dermatophytoses in Crete, Greece. Med. Mycol J. 57 (4), E69-E75. doi: 10.3314/mmj.16-00008

Martinez, L. R., and Casadevall, A. (2006). Susceptibility of Cryptococcus Neoformans Biofilms to Antifungal Agents in Vitro. Antimicrob. Agents Chemother. 50 (3), 1021-1033. doi: 10.1128/AAC.50.3.1021-1033.2006

Martinez, L. R., Mihu, M. R., Tar, M., Cordero, R. J. B., Han, G., Friedman, A. J., et al. (2010). Demonstration of Antibiofilm and Antifungal Efficacy of Chitosan Against Candidal Biofilms, Using an in Vivo Central Venous Catheter Model. J. Infect. Dis. 201 (9), 1436-1440. doi: 10.1086/651558

Medina-Alarcón kaila, P., Singulani,, JunPereira-da-silva, M. A., Pitangui, N. D. S., Santos, M. B., Ayusso, G. M., et al. (2020). Antifungal Activity of 2'Hydroxychalcone Loaded in Nanoemulsion Against Paracoccidiodes Spp. Future Microbiol. 15 (1), 21-33. doi: 10.2217/fmb-2019-0095

Melo, W. C. M. A., Santos, M. B. d., Marques B de, C., Regasini, L. O., Giannini, M. J. S. M., and Almeida, A. M. F. (2017). Selective Photoinactivation of Histoplasma Capsulatum by Water-Soluble Derivatives Chalcones. Photodiagnosis Photodyn. Ther. 18, 232-235. doi: 10.1016/j.pdpdt.2017.03.001

Moriello, K. A. (2004). Treatment of Dermatophytosis in Dogs and Cats: Review of Published Studies. Vet. Dermatol. 15 (2), 99-107. doi: 10.1111/j.13653164.2004.00361.x

Ochoa-pacheco, A., Arranz, J. C. E., Beaven, M., Peres-roses, R., Gámez, Y. M., Camacho-pozo, M. I., et al. (2017). Bioassay-Guided in Vitro Study of the Antimicrobial and Cytotoxic Properties of the Leaves From Excoecaria Lucida Sw. Pharmacognosy. Res. 9 (4), 396-400. doi: 10.4103/pr.pr_124_16

Oliveira, T. L., Medina-Alarcón kaila, P., Singulani, J. D. L., Fregonezi, N. F., Pires, R. H., Arthur, R. A., et al. (2020). Dynamics of Mono- and Dual-Species Biofilm Formation and Interactions Between Paracoccidioides Brasiliensis And Candida Albicans. Front. Microbiol. 11:551256. doi: 10.3389/fmicb.2020.551256

Ouf, S. A., Moussa, T. A., Abd-Elmegeed, A. M., and Eltahlawy, S. R. (2016). AntiFungal Potential of Ozone Against Some Dermatophytes. Braz. J. Microbiol. 47 (3), 697-702. doi: 10.1016/j.bjm.2016.04.014

Ouf, S. A., Taleb, A. M. A., Tharwat, N. A., and Geweely, N. S. (2013). Efficacy of Some Synthesized Thiazoles Against Dermatophytes. J. Mycol Med. 23 (4), 230-236. doi: 10.1016/j.mycmed.2013.07.056

Palanco, A. C., Lacorte Singulani, J., Costa-Orlandi, C. B., Gullo, F. P., Strohmayer Lourencetti, N. M., Gomes, P. C., et al. (2017). Activity of 3'-Hydroxychalcone Against Cryptococcus Gattii and Toxicity, and Efficacy in Alternative Animal Models. Future Microbiol. 12, 1123-1134. doi: 10.2217/fmb-2017-0062

Paz-Cristobal, M. P., Gilaberte, Y., Alejandre, C., Pardo, J., Revillo, M. J., and Rezusta, A. (2014). In Vitro Fungicidal Photodynamic Effect of Hypericin on 
Trichophyton Spp. Mycopathologia. 178 (3-4), 221-225. doi: 10.1007/s11046014-9797-6

Pierce, C. G., Uppuluri, P., Tristan, A. R., Wormley, F. L. Jr, Mowat, E., Ramage, G., et al. (2008). Lopez-Ribot JL. a Simple and Reproducible 96-Well PlateBased Method for the Formation of Fungal Biofilms and Its Application to Antifungal Susceptibility Testing. Nat. Protoc. 3 (9), 1494-1500. doi: 10.1038/ nport.2008.141

Santos, R. M., and Dias-Souza, M. V. (2017). Effectiveness of Five Antidandruff Cosmetic Formulations Against Planktonic Cells and Biofilms of Dermatophytes. Saudi J. Biol. Sci. 24 (2), 331-337. doi: 10.1016/j.sjbs.2015.09.033

Scorzoni, L., Benaducci, T., Almeida, A. M. F., Silva, D. H. S., Bolzani, V. D. S., and Gianinni, M. J. S. M. (2007). The Use of Standard Methodology for Determination of Antifungal Activity of Natural Products Against Medical Yeasts Candida Sp and Cryptococcus Sp. Braz. J. Microbiol. 38 (3), 391-397. doi: $10.1590 / S 1517-83822007000300001$

Scorzoni, L., Sangalli-Leite, F., de Lacorte Singulani, J., de Paula e Silva, A. C. A., Costa-Orlandi, C. B., Fusco-Almeida, A. M., et al. (2016). Searching New Antifungals: The Use of in Vitro and in Vivo Methods for Evaluation of Natural Compounds. J. Microbiol. Methods 123, 68-78. doi: 10.1016/ j.mimet.2016.02.005

Shah, M. S., Najam-ul-Haq, M., Shah, H. S., Farooq Rizvi, S. U., and Iqbal, J. (2018). Quinoline Containing Chalcone Derivatives as Cholinesterase Inhibitors and Their in Silico Modeling Studies. Comput. Biol. Chem. 76, 310-317. doi: 10.1016/j.compbiolchem.2018.08.003

Shamali, N., Preuß, A., Saltsman, I., Mahammed, A., Gross, Z., Däschlein, G., et al. (2018). In Vitro Photodynamic Inactivation (PDI) of Pathogenic Germs Inducing Onychomycosis. Photodiagnosis Photodyn. Ther. 24, 358-365. doi: 10.1016/j.pdpdt.2018.11.002

Shibu, E. S., Hamada, M., Murase, N., and Biju, V. (2013). Nanomaterials Formulations for Photothermal and Photodynamic Therapy of Cancer. J. Photochem Photobiol C Photochem Rev. 15 (1), 53-72. doi: 10.1016/ j.jphotochemrev.2012.09.004

Singh, G., Arora, A., Kalra, P., Maurya, I. K., Ruizc, C. E., Estebanc, M. A., et al. (2018b). A Strategic Approach to the Synthesis of Ferrocene Appended Chalcone Linked Triazole Allied Organosilatranes: Antibacterial, Antifungal, Antiparasitic and Antioxidant Studies. Bioorg. Med. Chem. 27 (1), 188-195. doi: 10.1016/j.bmc.2018.11.038

Singh, A., Masih, A., Khurana, A., Singh, P. K., Gupta, M., Hagen, F., et al. (2018a). High Terbinafine Resistance in Trichophyton Interdigitale Isolates in Delhi, India Harbouring Mutations in the Squalene Epoxidase Gene. Mycoses. 61 (7), 477-484. doi: 10.1111/myc. 12772

Singulani J de, L., Galeane, M. C., Ramos, M. D., Gomes, P. C., dos Santos, C. T., de Souza, B. M., et al. (2019). Antifungal Activity, Toxicity, and Membranolytic Action of a Mastoparan Analog Peptide. Front. Cell Infect. Microbiol. 9, 419. doi: $10.3389 /$ fcimb.2019.00419

Singulani, J. L., Scorzoni, L., Lourencetti, N. M. S., Oliveira, L. R., Conçolaro, R. S., da Silva, P. B., et al. (2018). Potential of the Association of Dodecyl Gallate With Nanostructured Lipid System as a Treatment for Paracoccidioidomycosis: in Vitro and in Vivo Efficacy and Toxicity. Int. J. Pharm. 547 (1-2), 630-636. doi: 10.1016/j.ijpharm.2018.06.013

Sun, K., Song, X., Jia, R. Y., Yin, Z., Zou, Y., Li, L., et al. (2017). In Vivo Evaluation of Galla Chinensis Solution in the Topical Treatment of Dermatophytosis.
Evidence-Based Complement Evid Based Complement Alternat Med. 2017, 3843595. doi: 10.1155/2017/3843595

Tajuddeen, N., Isah, M. B., Suleiman, M. A., van Heerden, F. R., and Ibrahim, M. A. (2018), the Chemotherapeutic Potential of Chalcones Against Leishmaniases: A Review. Int. J. Antimicrob. Agents 51 (3), 311-318. doi: 10.1016/j.ijantimicag.2017.06.010

Tavares, L. D. C., Johann, S., Maria De Almeida Alves, T., Guerra, J. C., Maria De Souza-Fagundes, E., Cisalpino, P. S., et al. (2011). Quinolinyl and Quinolinyl N-Oxide Chalcones: Synthesis, Antifungal and Cytotoxic Activities. Eur. J. Med. Chem. 46 (9), 4448-4456. doi: 10.1016/j.ejmech.2011.07.019

Toukabri, N., Corpologno, S., Bougnoux, M. E., El Euch, D., Sadfi-Zouaoui, N., and Simonetti, G. (2018). in Vitro Biofilms and Antifungal Susceptibility of Dermatophyte and Non-Dermatophyte Moulds Involved in Foot Mycosis. Mycoses. 61 (2), 79-87. doi: 10.1111/myc.12706

Yang, Y., Hou, W., Liu, S., Sun, K., Li, M., and Wu, C. (2018). Biodegradable Polymer Nanoparticles for Photodynamic Therapy by Bioluminescence Resonance Energy Transfer. Biomacromolecules. 19 (1), 201-208. doi: 10.1021/acs.biomac.7b01469

Yang, Y., Wang, C., Zhuge, Y., Zhang, J., Xu, K., Zhang, Q., et al. (2019). Photodynamic Antifungal Activity of Hypocrellin a Against Candida Albicans. Front. Microbiol. 10, 1810. doi: 10.3389/fmicb.2019.01810

Yoo, J. O., and Ha, K. S. (2012). New Insights Into the Mechanisms for Photodynamic Therapy-Induced Cancer Cell Death. Int. Rev. Cell Mol. Biol. 295, 139-174. doi: 10.1016/B978-0-12-394306-4.00010-1

Yuan, Y., Liu, Z., Jin, H., Sun, S., Liu, T., Wang, X., et al. (2017). Photodynamic Antimicrobial Chemotherapy With the Novel Amino Acid-Porphyrin Conjugate 4I : in Vitro and in Vivo Studies. PloS One 12 (5), e0176529. doi: 10.1371/journal.pone.0176529

Zhang, J., Jiang, C., Longo, J. P. F., Azevedo, R. B., Zhang, H., and Muehlmann, L. A. (2018a). an Updated Overview on the Development of New Photosensitizers for Anticancer Photodynamic Therapy. Acta. Pharm. Sin. B. 8 (2), 137-146. doi: 10.1016/j.apsb.2017.09.003

Zhang, X., Rakesh, K. P., Bukhari, S. N. A., Balakrishna, M., Manukumar, H. M., and Qin, H. L. (2018b). Multi-Targetable Chalcone Analogs to Treat Deadly Alzheimer's Disease: Current View and Upcoming Advice. Bioorg. Chem. 80, 86-93. doi: 10.1016/j.bioorg.2018.06.009

Zhan, P., and Liu, W. (2017). The Changing Face of Dermatophytic Infections Worldwide. Mycopathologia. 182 (1-2), 77-86. doi: 10.1007/s11046-016-0082-8

Zhuang, C., Zhang, W., Sheng, C., Zhang, W., Xing, C., and Miao, Z. (2018). Chalcone: A Privileged Structure in Medicinal Chemistry. Chem. Rev. 117 (12), 7762-7810. doi: 10.1021/acs.chemrev.7b0002

Conflict of Interest: The authors declare that the research was conducted in the absence of any commercial or financial relationships that could be construed as a potential conflict of interest.

Copyright (๑ 2021 Bila, Costa-Orlandi, Vaso, Bonatti, de Assis, Regasini, Fontana, Fusco-Almeida and Mendes-Giannini. This is an open-access article distributed under the terms of the Creative Commons Attribution License (CC BY). The use, distribution or reproduction in other forums is permitted, provided the original author(s) and the copyright owner(s) are credited and that the original publication in this journal is cited, in accordance with accepted academic practice. No use, distribution or reproduction is permitted which does not comply with these terms. 